\title{
Comparison of Obesity Bias, Attitudes, and Beliefs among Undergraduate Dietetic Students, Dietetic Interns, and Practicing Registered Dietitians
}

Sarah E. Welborn

East Tennessee State University

Follow this and additional works at: https://dc.etsu.edu/etd

Part of the Dietetics and Clinical Nutrition Commons

\section{Recommended Citation}

Welborn, Sarah E., "Comparison of Obesity Bias, Attitudes, and Beliefs among Undergraduate Dietetic Students, Dietetic Interns, and Practicing Registered Dietitians" (2013). Electronic Theses and Dissertations. Paper 1104. https://dc.etsu.edu/etd/1104

This Thesis - Open Access is brought to you for free and open access by the Student Works at Digital Commons @ East Tennessee State University. It has been accepted for inclusion in Electronic Theses and Dissertations by an authorized administrator of Digital Commons @ East Tennessee State

University. For more information, please contact digilib@etsu.edu. 
Comparison of Obesity Bias, Attitudes, and Beliefs Among Undergraduate Dietetic Students, Dietetic Interns, and Practicing Registered Dietitians

\author{
A thesis \\ presented to \\ the faculty of the Department of Allied Health Sciences \\ East Tennessee State University
}

In partial fulfillment

of the requirements for the degree

Master of Science in Clinical Nutrition

by

Sarah Elizabeth Welborn

May 2013

\author{
Michelle Lee, Ph.D., R.D., Committee Chair \\ Eileen Cress, M.S., R.D., Committee Member \\ Michelle Johnson, M.S., R.D., Committee Member
}

Keywords: obesity bias, weight bias, fat phobia, obesity, nutrition 


\begin{abstract}
Comparison of Obesity Bias, Attitudes, and Beliefs among Undergraduate Dietetic Students, Dietetic Interns, and Practicing Registered Dietitians

by

Sarah Elizabeth Welborn
\end{abstract}

The obesity epidemic in the United States is increasing, and health concerns are also on the rise as they are directly related to obesity. Even though the majority of Americans are overweight or obese, prejudice and weight bias continue to be prevalent and socially accepted in a culture that tolerates discrimination towards these individuals. Health care providers, including registered dietitians, are not exempt from instigating bias towards obese patients causing a decrease in the level of care that they receive. The main purpose of this study was to compare attitudes, beliefs, and bias concerning obesity among undergraduate dietetic students, dietetic interns, and practicing registered dietitians. The data were reported directly by participants. No significant difference was found between fat phobia scores of students, interns, and dietitians. However, it was found that obesity bias decreased slightly as one moved through the dietetics profession. Also, Body Mass Index and fat phobia scores were negatively correlated. 


\section{ACKOWLEDGEMENTS}

My sincerest thanks and gratitude to all of those who helped make this project possible, especially:

Dr. Michelle Lee for taking on this project with me and seeing it through to completion. Thank you for helping me see the light at the end of the tunnel when it became difficult to do so. Thank you for your guidance, support, expertise, and constructive criticism along the way. This project could not have been completed without you.

Mrs. Eileen Cress for your sense of humor and always making me laugh when I needed it and for finding every comma that I left out among other inconsistencies.

Mrs. Michelle Johnson for consistently asking me how the research, writing, and editing was going throughout this entire process and for the times that you talked me through the process so that I could get something down on paper.

Dr. Lisa Sheehan-Smith for your guidance and advice that motivated me to take on this project and for your help in data collection. Thank you for your continued support and encouragement as I entered graduate school.

Mrs. Ginny Bogle for your guidance, advice, and dedication throughout the years. Our talks early on in this project inspired me- thank you for helping me see the vision I had for this project. Your continued friendship and support means the world to me.

My family and friends for your love, encouragement, and support.

Courtney and Monique for sharing this thesis journey with me, for the encouraging pep talks when I needed it, and supporting each other throughout. We did it!

My roommate and fellow intern, Rachel, for your friendship, support, and encouragement. Thank you for providing comic relief when I needed it the most.

My fiancé, Daniel, thank you for everything that you have done for me. You will never know how much I have leaned on you for support, and I hope I can return the favor one day. Thank you for sharing in this journey with me and believing in me. I love you very much!

Most importantly, God, for blessing me with a passion for nutrition, writing, and the strength needed to see it through; for His Word that reminded me of such promises- Philippians $4: 13$. 


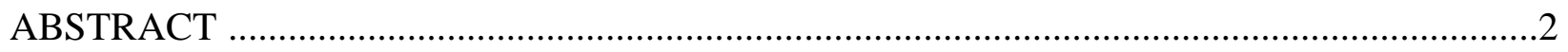

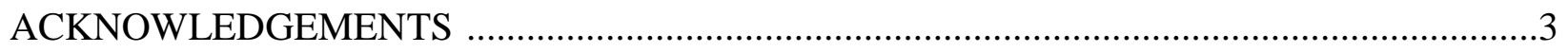

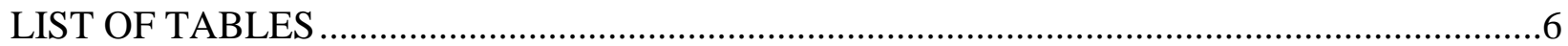

Chapter

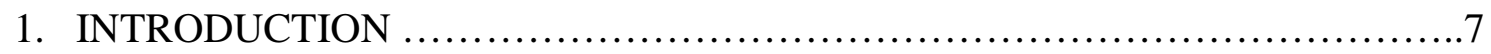

Rationale ...................................................................

2. REVIEW OF THE LITERATURE .........................................11

Definition and Prevalence of Overweight and Obesity ........................11

Obesity Bias, Fat Phobia, and Attitudes Concerning Obesity ...................12

Consequences of Obesity Bias, Fat Phobia, and Negative Attitudes .............15

Obesity Bias Among the Health Care System...................................18

Obesity Bias and the Dietetics Profession ................................... .21

Concerns, Awareness, and Interventions of Obesity Bias ......................23

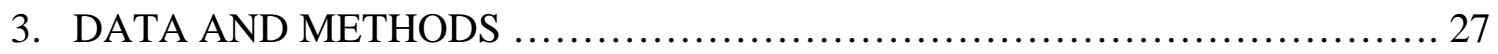

Participants and Sample ................................................ 27

Instrumentation ........................................................... 27

Data Collection ...................................................... 29

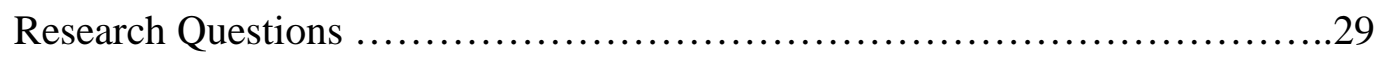

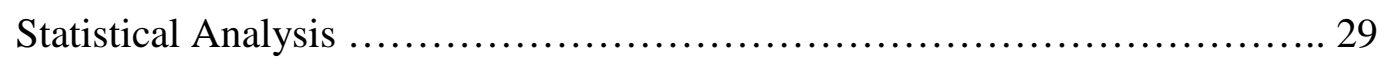

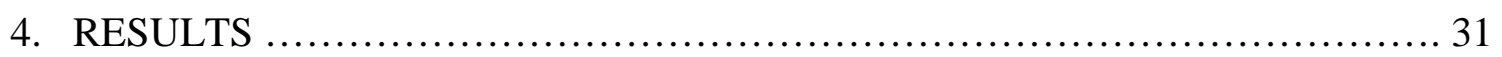

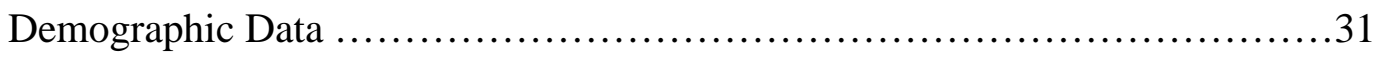

Demographics Specific to Practicing Registered Dietitians ..................... 32

The Relationship Between BMI and Fat Phobia Scores ........................ 34 
Comparisons of Fat Phobia Scores Among Students, Interns, and Dietitians .... 35

5. CONCLUSIONS AND IMPLICATIONS ................................ 39

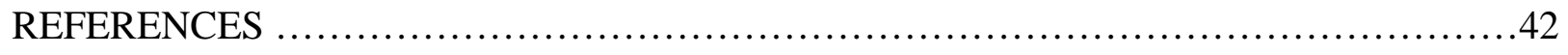

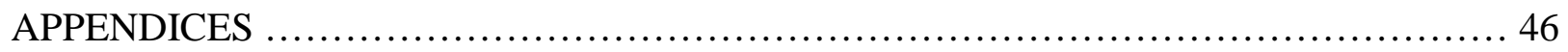

Appendix A: Institutional Review Board Letter of Approval ...................... 46

Appendix B: Survey Documents for Students and Interns $\ldots \ldots \ldots \ldots \ldots \ldots \ldots \ldots \ldots \ldots . .47$

Appendix C: Survey Documents for Registered Dietitians .......................51

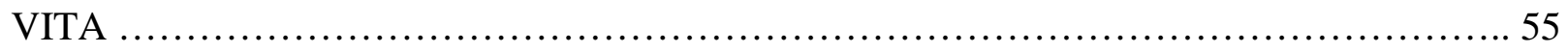




\section{LIST OF TABLES}

Table

1. Definition of Terms ..............................................................

2. Demographic of all Survey Participants .........................................32

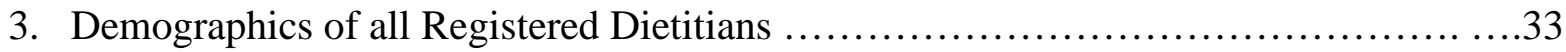

4. Correlation Coefficients of the Fat Phobia Survey and the Anti-fat Attitude Survey Between Students, Interns, and Registered Dietitians ............................35

5. Means \pm SD of Anti-fat Attitude Questionnaire and Fat Phobia Scale to Determine Weight Bias among Undergraduate DPD Students, Dietetic Interns, and Practicing

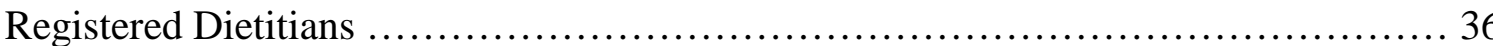




\section{CHAPTER 1}

\section{INTRODUCTION}

\section{Rationale}

The obesity epidemic in the United States is steadily increasing, and current statistics indicate that $68 \%$ of adults in the United States are overweight or obese, with $34 \%$ being classified as obese on the Body Mass Index (BMI) scale. ${ }^{1}$ In relation to this, health concerns are on the rise as well as they are related to overweight and obesity. Obese individuals are at a greater risk for developing type 2 diabetes mellitus, cardiovascular disease, hypertension, cancers, and stroke. ${ }^{2}$ Even though the majority of Americans are overweight or obese, prejudice and weight bias continue to be prevalent and socially accepted in a culture that tolerates discrimination towards overweight and obese individuals.

Table 1 introduces definitions of terms related to weight bias and notes that weight bias can also be referred to as a fat phobia in which people fear fatness that can lead to a manifestation of negative attitudes and stereotypes about overweight and obese individuals. ${ }^{3}$ These negative attitudes and stereotypes include opinions that overweight and obese people are undisciplined, inactive, unappealing, and have poor hygiene. ${ }^{4}$ Such attitudes can have physical and emotional consequences on obese individuals including psychological effects as well as effects on eating and physical activity. ${ }^{5}$ Psychological consequences include depression, suicide attempts, low self-esteem, and dissatisfaction concerning body image. ${ }^{5,6}$ Some individuals may choose not to engage in physical activity as a reaction to obesity bias, while others may have eating disturbances as a direct result from weight-related teasing. ${ }^{5}$

The health care system and its providers are not exempt from instigating obesity bias. According to opinion-based surveys distributed by the Rudd Center, more than $50 \%$ of primary care physicians viewed their obese patients as “awkward, unattractive, ugly, and noncompliant”. 7 
These prejudicial attitudes concerning obesity are widespread throughout the healthcare system and include doctors, nurses, dietitians, and students pursuing degree in these fields. ${ }^{4}$ Weight bias in the health care setting is not limited to verbal comments; nonverbal behaviors are prevalent and include facial expressions and inappropriate gestures. ${ }^{5}$ Overweight and obese patients can also be indirectly affected by there not being adequate medical equipment to accommodate them such as patient gowns, scales, and blood pressure cuffs. ${ }^{5}$

Obesity bias has also made its way into the dietetics profession and is even seen in undergraduate and graduate students. This is of concern because a dietitian's role is to counsel overweight and obese individuals, help them set realistic goals, and support them as they strive to reach their weight loss goals. Surveys and studies have found that some dietitians believe that overweight clients cannot set realistic goals for weight loss and contribute emotional stress to their weight problems. ${ }^{5,8}$ Other studies indicate that dietetic students also exhibit obesity bias and deem obese patients as less likely than nonobese patients to comply with treatment recommendations. ${ }^{7}$ Even when provided with information suggesting a healthy lifestyle, dietetic students make assumptions that obese individuals have poorer diets, a lack of physical activity, and overall worse health than those who maintain a normal weight. ${ }^{7}$

These findings among other health care providers, as well as the dietetics profession alone, raise concerns and shed light on the need for an increase in sensitivity toward overweight and obese clients. ${ }^{5}$ This is crucial, as the number of obese clients increases, so that treatment practices increase in effectiveness. Initiating awareness and education of obesity bias among dietetics students will counteract negative assumptions about obese patients so that treatment practices of future dietitians are not jeopardized. ${ }^{7}$ Fat phobia attitudes and perceptions can be improved through interventions designed to increase positive perceptions about overweight and 
obese people, leading to a rise in client's self-esteem. ${ }^{3}$ By improving self-awareness of personal bias and taking actions to reduce obesity bias, dietitians can play a crucial role in providing sensitive care to overweight and obese clients while assisting them in promoting healthy lifestyle changes and behaviors. ${ }^{5}$

Obesity is a national epidemic with approximately $68 \%$ of adults in the United States being overweight and obese. ${ }^{1}$ According to the Center for Disease Control, Tennessee is ranked as the fourth most obese state in the United Stated with $31.7 \%$ of Tennesseans being obese in 2010 and $68.7 \%$ of Tennesseans being overweight or obese in $2010 .{ }^{1}$ This obesity epidemic affects health care providers as well, including registered dietitians. The purpose of this research is to compare attitudes, beliefs, and bias concerning obesity among undergraduate dietetics students, dietetic interns, and practicing registered dietitians in Middle Tennessee, East Tennessee, and Northeast Mississippi. 
Table 1: Definition of Terms

\begin{tabular}{|c|c|}
\hline Term & Definition \\
\hline Attitudes & $\begin{array}{l}\text { The way a person views something or tends to behave towards it, } \\
\text { often in an evaluative way. }\end{array}$ \\
\hline$B M I$ & Body Mass Index, calculated by weight [kg]/height [m] ${ }^{29}$ \\
\hline Cardiovascular Disease & A general term for all diseases of the heart and blood vessels. ${ }^{9}$ \\
\hline$C D C$ & Centers for Disease Control and Prevention. \\
\hline Fat Phobia & The fear of fatness. \\
\hline Hypertension & Higher-than-normal blood pressure. $^{9}$ \\
\hline Obesity & $\begin{array}{l}\text { A description used to classify one with a Body Mass Index of } 30 \text { or } \\
\text { higher. }\end{array}$ \\
\hline Obesity Bias & $\begin{array}{l}\text { Negative attitudes and assumptions towards obese people based on } \\
\text { physical appearance. }\end{array}$ \\
\hline Overweight & $\begin{array}{l}\text { A description used to classify one with a Body Mass Index of } 25 \text { to } \\
\text { 29.9.9 }\end{array}$ \\
\hline Stroke & $\begin{array}{l}\text { An event in which the blood flow to a part of the brain is cut off; also } \\
\text { called a cerebrovascular accident. }{ }^{9}\end{array}$ \\
\hline Type 2 Diabetes Mellitus & $\begin{array}{l}\text { A chronic disorder of carbohydrate metabolism, usually resulting } \\
\text { from insufficient or ineffective insulin. }{ }^{9}\end{array}$ \\
\hline Weight Bias & $\begin{array}{l}\text { The mental tendency or inclination, especially an irrational } \\
\text { preference or prejudice based on weight. }\end{array}$ \\
\hline
\end{tabular}




\section{CHAPTER 2}

\section{REVIEW OF THE LITERATURE \\ Definition and Prevalence of Overweight and Obesity}

Overweight and obesity are terms used to describe and categorize excess weight above what is considered normal for an individual's height. Typically, overweight and obesity are defined and categorized using the Body Mass Index (BMI) scale, which takes into account an individual's height and weight. The formula used to calculate BMI is weight $[\mathrm{kg}] /$ height $[\mathrm{m}]^{2}$, and the resulting number is related to the amount of body fat. ${ }^{9}$ An individual's BMI and amount of body fat can be directly related to nutritional risk factors and other comorbidities. Overweight is defined as a BMI of 25 to $29.9 \mathrm{~kg} / \mathrm{m}^{2}$, and obesity is defined as a BMI of $30 \mathrm{~kg} / \mathrm{m}^{2}$ or higher. Although BMI is related to an individual's amount of body fat, it does not directly measure body fat. ${ }^{10}$ Also, it does not take into account one's muscle mass; for example, a football player with a BMI of $26 \mathrm{~kg} / \mathrm{m}^{2}$ may be lean and fit but overweight according to the BMI scale.

Over the past 2 decades, overweight and obesity rates in the United States have steadily risen. Current statistics indicate that $68 \%$ of adults in the United States are overweight or obese, with half of these being obese. ${ }^{1}$ Approximately $17 \%$ of children and adolescents aged 2-19 years in the United States are obese. ${ }^{1}$ In 2000, the obesity prevalence per state was less than $30 \%$, but, by 2010, twelve states had an obesity prevalence of 30\% or more and included Alabama, Kentucky, Louisiana, Mississippi, South Carolina, West Virginia, and Tennessee indicating that the South has the highest prevalence of obesity at $29.4 \% .{ }^{1}$

Current statistics indicate that Mississippi is the most obese state followed closely by fourth ranked Tennessee. Mississippi obesity rates rose from 10\% to $14 \%$ in 1990 to $20 \%$ to $24 \%$ in 2010. By 2010, Mississippi’s obesity rate was greater than 30\% and it became the most obese 
state with $34 \%$ of its population being obese. ${ }^{1}$ In 1985 , Tennessee’s obesity rate was less than $10 \%$ and, by 1995 , it was between $15 \%$ and $19 \%$. By 2005 , the Tennessee obesity rate reached 25\% to 29\%. ${ }^{1}$ According to the Center for Disease Control, in 2011, Tennessee became the fourth most obese state in the United States with 31.7\% of Tennesseans being obese in 2010 and $68.7 \%$ of Tennesseans being overweight or obese in $2010 .^{1}$

In conjunction with rising obesity rates, health concerns related to obesity are also on the rise in the United States. ${ }^{2}$ These health concerns include other diseases such as type 2 diabetes mellitus, cardiovascular disease, hypertension, and certain types of cancers. Being overweight or obese automatically puts an individual at a higher risk for developing one or more of these diseases.

\section{Obesity Bias, Fat Phobia, and Attitudes Concerning Obesity}

Even though America is an overweight and obese nation, weight bias is prevalent and prejudice and discrimination against the overweight/obese population is rampant and tolerated. Weight bias is a fat phobia that leads to manifestations of negative attitudes and stereotypes concerning overweight and obese individuals. ${ }^{3}$ These negative attitudes and stereotypes include opinions that overweight and obese people are undisciplined, inactive, and unappealing and have poor hygiene. ${ }^{4}$ Fat phobia also plays into these negative attitudes as it is the pathological fear of fatness, the fear of the obese, and the fear of becoming fat. ${ }^{11,12}$ In general, individuals with obesity more often experience day-to-day interpersonal and lifetime discrimination than those who are of a normal weight. ${ }^{13,14}$

Weight bias attitudes are fueled by attributing the controllability of weight and North American values of individualism with the belief that people are responsible for their life situation. ${ }^{15,16,17}$ When approaching an obese person, people may search for its cause and then 
form their reactions to that person. ${ }^{18}$ This attribution theory shows that a person will blame and stigmatize an obese person if he/she believes that the individual is responsible for his/her fatness. ${ }^{18,19,20}$ Weight bias can be divided into two categories: explicit bias and implicit bias. Explicit bias is consciously choosing to express negative attitudes that may include "obese people lack self-control and are lazy, obesity is caused by character flaws, and failure to lose weight is due only to noncompliance”. ${ }^{21,22}$ Explicit weight bias might also include inappropriate verbal comments including derogatory remarks, insults, and jokes; however, it can also include nonverbal behaviors such as inappropriate gestures and facial expressions. ${ }^{5}$ Implicit weight bias includes biases that are beyond conscious awareness because they are ingrained in a person's mind, and measuring such attitudes requires methods for studying these attitudes that go beyond one’s awareness. ${ }^{21,22}$

Explicit weight bias attitudes are generally measured by pencil and paper surveys; ${ }^{21}$ an example of one of these surveys is the fat phobia scale. In 1984, Robinson, Bacon, and O’Reilly developed the 50-item, 5-point semantic differential fat phobia scale by drawing from their clinical experience and from adjectives used to describe fat people, which they gathered from a sample of people who entered a Minnesota motor vehicle license bureau. ${ }^{4}$ From this, they conducted an analysis on a large sample of people $(n=1135)$ interested in body image and weight. From this analysis, they determined 6 distinct fat phobia subscales that included “undisciplined; inactive and unappealing; grouchy and unfriendly; poor hygiene; passivity; emotional/psychological problems; and stupid and uncreative”. Another example of a survey measuring explicit bias is the Antifat Attitudes Questionnaire. This survey has 3 parts that measures an individual's bias concerning the dislike of fat, the fear of fat, and willpower. ${ }^{19}$ The “dislike” section poses questions or statements concerning number of fat friends, family 
members, and comfort levels associated with the overweight and obese population. The "fear of fat" section poses personal questions about the fear of gaining weight, past weight problems, and feelings associated with weight gain. Finally, the "willpower" section assesses whether or not people blame an overweight or obese person for their weight gain and, if they do, whether they attribute it to lack of willpower, laziness, or other faults. ${ }^{19}$

Overweight and obese individuals face discrimination and negative stereotypes such as the ones previously mentioned on a daily, lifelong basis. Obese children and adults alike face discrimination and prejudice interpersonally, professionally, and educationally in addition to healthcare settings. ${ }^{14}$ Hansson, Naslund, and Rasmussen conducted a study of perceived discrimination among obese men and women using a questionnaire that assessed perceived lifetime and interpersonal discrimination ( $\mathrm{n}=2788)$. They concluded that workplace discrimination was prevalent in both moderately and severely obese individuals, and the magnitude of discrimination was similar. However, the pattern of discrimination in the professional sense was different between men and women in that "for women, only severe obesity was found to be of importance regarding workplace discrimination”. ${ }^{14}$ Several explanations for this include the following: 1) moderately obese men hold high-status jobs more often than severely obese men and, with pressures towards thinness being stronger among higher socioeconomic classes, experience more prejudice; 2) prejudice and discrimination can be stronger for both obese men and women of higher socioeconomic status. ${ }^{14}$

Hansson, Naslund, and Rasmussen also determined that there are strong associations between severe obesity, socioeconomic status, education level, and healthcare. Two explanations for this include the following: 1) highly educated individuals expect to be respected and not mistreated; therefore, they report higher levels of discrimination than lower educated individuals; 
2) on the contrary, "healthcare professionals may be less tolerant of obese people with high education because they are of the opinion that highly educated people should know better how to stay healthy”. ${ }^{14}$ In addition to this, they concluded that, due to society's emphasis on thinness, women may endure negative remarks, prejudice, and discrimination to a higher extent than men, and, "unlike men, women may also experience negative treatment due to obesity during all stages of life". ${ }^{14}$

Educational discrimination is an issue in all settings including elementary school, middle school, high school, college, and graduate studies. Discrimination can begin with harassment and rejection from peers at school to teachers with negative attitudes towards overweight and obese children; it can also include lower college acceptance as well as wrongful dismissals from college. $^{18}$

The media also play a role in discrimination against the overweight and obese population in the way that they are portrayed on television, movies, and the radio. For example, children's cartoons may ridicule characters who are overweight, overweight characters may be cast in negative ways in movies, and fat jokes have become common in various television shows and commercials. ${ }^{18}$

\section{Consequences of Obesity Bias, Fat Phobia, and Negative Attitudes}

Obesity bias, discrimination based on weight, and the negative attitudes that intertwine the two can have physical, emotional, and social consequences on obese individuals including psychological effects as well as effects on eating and physical activity. ${ }^{5}$ Psychological consequences may include depression, suicide attempts, low self-esteem, and dissatisfaction with body image. ${ }^{5,}$, 23-25 It is not known whether or not an individual's low self-esteem ensues from being overweight or obese, the teasing related to weight, or a combination of both. In addition to 
this, some individuals may choose not to engage in physical activity as a reaction to weight bias, while others may have eating disturbances as a direct result from weight-related teasing. ${ }^{25}$

Adults with a documented history of weight-related teasing are likely to have eating disturbances directly related to such teasing, as evidenced in a study by Garner, Olmsted, Bohr, and Garfinkel. ${ }^{5,26}$ Using the Eating Attitudes Test (EAT), which is an objective, self-report measure of the symptoms of anorexia nervosa, they conducted a study on 160 female anorexia nervosa patients and 140 female comparison subjects to determine that "EAT scores were independent of weight but were related to emotional disturbance" ${ }^{26}$ Subjects were also asked to take a Body Dissatisfaction Scale (BDS) test in which body parts were listed, and, on a scale of 1 to 6 , subjects rated satisfaction or dissatisfaction with the given body parts. From this, they determined a body-image composite score for each test subject. Garner, Olmsted, Bohr, and Garfinkel determined that those anorexia nervosa patients who had experienced teasing earlier in life were more likely to possess a pathological avoidance of fattening foods, as well as preoccupations with body shape and body-image disturbances. ${ }^{26}$

In conjunction with this, other studies have found that bulimia nervosa and binge eating disorders among adults are more common in those who endured "childhood weight-related teasing and negative comments by family members about weight, shape, or eating while growing up”. ${ }^{5}$ In a study by Jackson, Grilo, and Masheb, 115 female adults with binge eating disorder were examined to determine the associations between teasing history, onset of obesity, and body dissatisfaction. Measurements assessed 2 types of teasing: 1) general appearance and 2) weight and size. ${ }^{27}$ They determined that history of general appearance teasing was associated with body dissatisfaction and current weight concerns, whereas weight and size teasing was not; however, both forms of teasing were significantly related to depression and self-esteem.${ }^{27}$ Jackson and 
associates also determined that weight and size teasing positively correlated with an early onset of obesity, as opposed to a late onset of obesity. Most notably, physical appearance teasing history was found to have the strongest effect on an individual's body dissatisfaction, level of depression, and self-esteem. ${ }^{27}$

Weight-related teasing or weight criticism during physical activities can have physical as well as emotional consequences and may also serve as a barrier to adopting or maintaining a healthy lifestyle. ${ }^{22,28}$ Teasing during such times can lead to lower levels of physical activity, less enjoyment of sports, and preferring isolated, sedentary activities. ${ }^{28,29}$ In a study of 576 fifth through eighth graders, Faith, Leone, Ayers, Heo, and Pietrobelli tested the association of weight criticism during physical activity (WCA) with the children's attitudes towards physical activity and exercise. Results indicated that weight criticism during physical activity was more common among heavier girls than boys and concluded that it was "associated with reduced sports enjoyment, perceived activity compared to peers, and mild-intensity leisure activity”. ${ }^{28}$ In relation to this, other studies have found that peer to peer teasing in children is positively related to depression, anxiety, and loneliness while being negatively related to physical activity. ${ }^{29}$

Research has indicated that individuals will respond to teasing and criticism in different ways, but that they all will use a coping mechanism to deal with the emotions and consequences that are left behind. One coping mechanism used is that of self-acceptance in which an individual conforms to the negative stereotype and internalizes that his/her body is a "bad body";22 this conformation of a negative stereotype is associated with increased levels of depression, hostility, and other negative affects. ${ }^{22,30,31}$ Other coping strategies that overweight and obese adults might use in retaliation to discrimination or teasing include humor, joking, insulting back, and physical violence. ${ }^{22,24,25}$ In relation to this, gender differences concerning coping mechanisms do exist in 
that "women more often use emotion-focused or social support coping strategies to handle stressors, whereas men are more likely to employ aggressive and antisocial strategies and respond to the stressors in a direct way". ${ }^{22}$

Finally, it is important to understand that obese people often internalize societal pro-thin and anti-fat biases leading to society’s and personal assessment that an imperfect body represents an imperfect person. ${ }^{21}$ This perception, combined with constant discrimination, leads to additional effects on an obese individual's health due to added stress. ${ }^{14,} 32$ These negative emotions can trigger anxiety and depression that may affect behavior as well as psychological processes. ${ }^{14,32}$ Because stress-related experiences of discrimination, teasing, and bias may increase the risk of further weight gain, ${ }^{33}$ it is important to note the possible "interplay between the risk factor of being discriminated against (obesity) and the outcomes of being discriminated against (weight gain)”. 14

\section{Obesity Bias Among the Health Care System}

Obesity bias is prevalent across the United States population, and the health care system and its providers are not exempt from instigating such discrimination and attitudes towards the people they serve. In fact, prejudicial attitudes concerning overweight and obesity are widespread throughout the health care spectrum and include doctors, nurses, dietitians, and students pursuing degrees in these various fields. ${ }^{4}$ Such bias concerning an individual's weight is not limited to verbal comments; nonverbal behaviors are prevalent and include facial expressions and inappropriate gestures. ${ }^{5,34}$ Also, overweight and obese patients can be indirectly affected by inadequate medical equipment to accommodate them such as gowns, scales, and blood pressure cuffs. $^{5,34}$ 
According to opinion-based surveys distributed by the Rudd Center, more than $50 \%$ of primary care physicians viewed their obese patients as "awkward, unattractive, ugly, and noncompliant" ${ }^{6}$ This can have a significant impact on the effectiveness of care given to patients as well as return visits from patients who are overweight or obese; some patients may choose to neglect health care altogether due to past uncomfortable or discriminatory experiences. For example, one study of 489 female subjects found that obese women were more likely to avoid or delay cancer screenings than thinner women. ${ }^{5,35}$ Barriers that attributed to their decisions included "disrespectful treatment and negative attitudes from providers, unsolicited advice to lose weight, embarrassment of being weighed, and medical equipment that was too small for their body size" ${ }^{5,35}$ The percentage of subjects reporting such barriers was directly related to body mass index. ${ }^{5}$

In conjunction with this, obese individuals may choose not to seek medical assistance for weight loss due to previous discriminatory actions and biases. Also of equal concern is that antifat attitudes among health care professionals may affect their clinical judgment, which can also lead to patients' neglect to seek medical advice. Drury and Louis conducted a study of 216 women to explore and determine the stigma of obesity and its effect on the use of health care as related to body mass index and satisfaction with previous medical care. Participants completed a questionnaire that gathered information concerning three topics: 1) body mass index; 2) delay/avoidance of health care; and 3) esteem, satisfaction with medical care, attribution. ${ }^{36}$ The authors concluded that reasons for delaying or avoiding health care visits included both nonweight-related as well as weight-related reasons. The most common weight-related reasons for delaying health care included "having gained weight since the last health care visit" and "not 
wanting to get weighed on the scale". ${ }^{36}$ Facial expressions, comments, and other nonverbal behaviors also act as barriers to patients when deciding to delay or avoid health care visits. ${ }^{36,37}$

The perceptions of nurses have also been studied and were found to be similar to those of physicians and nurse practitioners. A study of nurses $(\mathrm{n}=586)$ examined beliefs about the causes of obesity and found that nurses rated noncompliance as the most likely reason for overweight and obese patients' inability to lose weight. ${ }^{34,38}$ In a similar study, $63 \%$ of participating nurses agreed that obesity can be prevented by self-control and, often, obese patients can be lazy (22\%) and overindulgent (43\%). ${ }^{34,39}$ These attitudes and perceptions most likely stemmed from the fact that $48 \%$ of the participating nurses stated that they felt uncomfortable caring for obese patients while $31 \%$ stated that they would prefer not to care for the obese population at all. ${ }^{34,39}$

Also, it has been speculated that obese individuals receive less blame and less undesirable attitudes from others, particularly health care professionals, when their obesity can be attributed to a physical cause outside of their personal control that would negate assumptions of laziness and self-indulgence. ${ }^{5}$ In one study, 2 experiments were conducted to determine adolescent girls' opinions of an obese peer after they were given 2 different explanations for the cause of the peer's obesity. The authors determined that the peer was accepted and given a positive evaluation by the other girls if an "excuse for her weight, such as a glandular disorder," was stated. $^{5,40}$

It is crucial that health care professionals become aware of their biases, perceptions, and negative attitudes towards the overweight and obese population in order to prevent them from hindering care to this population. It is of equal importance for health care students to become aware of their own biases, perceptions, and attitudes about the overweight and obese population before dealing with weight management clients. ${ }^{12}$ Health care professionals can be beneficial in 
educating students about the complexity of obesity by communicating positive attitudes concerning the obese population. ${ }^{15}$ This will be beneficial in eradicating negative attitudes about the obese population so that obese individuals do not face additional health consequences resulting from obesity bias. ${ }^{15}$

\section{Obesity Bias and the Dietetics Profession}

Obesity bias, as well as the negative attitudes and perceptions that accompany it, has made its way into the dietetics profession and is even seen in undergraduate and graduate students. This is of major concern because a crucial role in the dietetics field is that of counseling overweight and obese individuals, helping them set realistic goals, and supporting them as they strive to reach their weight loss goals. Unfortunately, these negative attitudes can have an impact on management practices used by registered dietitians. ${ }^{37,41}$

Studies and surveys have found that some registered dietitians believe that overweight and obese clients cannot set realistic weight loss goals and contribute emotional stress to their weight problems. ${ }^{5,}$ In a study examining registered dietitians' (n=234) and dietetic students' ( $n=64)$ attitudes towards obesity, negative attitudes were reported by both groups and those who expressed greater negative attitudes towards obesity rated themselves as "healthful weight" or “underweight”; those who rated themselves as “overweight” did not possess negative attitudes to the degree of their healthy weight colleagues. ${ }^{5,42}$

Other studies indicate that dietetic students also exhibit obesity bias and deem obese patients as less likely than non-obese patients to comply with treatment recommendations. ${ }^{7}$ Even when provided with information suggesting a healthy lifestyle, dietetic students made assumptions that overweight and obese individuals had poorer diets, a lack of physical activity, and overall worse health than those who maintain a normal weight. ${ }^{7}$ In a study comparing 
negative attitudes of dietetics students and non-dietetics students, researchers determined that there was "no difference in overall attitudes between dietetics students and a control group consisting of age- and weight-matched students from a variety of non-health disciplines”. ${ }^{37}$ This indicates that society plays a crucial role in these prejudicial attitudes and that dietetics education does not promote them but also does not negate them in dietetic students. This is of concern because such attitudes may influence their ability to counsel overweight and obese individuals in a clinical setting.

Measures should be taken to increase awareness of obesity bias among the dietetic profession as well as increase sensitivity towards the obese population. Steps toward sensitivity include practicing sensitive communication, weighing with care, and ensuring a safe office environment. ${ }^{5}$ Before a dietitian can practice sensitive communication, he or she must be aware that his or her assumptions and stereotypes can be expressed in nonverbal behaviors such as gestures and facial expressions in conjunction with verbal comments that may be perceived and received negatively by the client or patient. This, in turn, could ultimately jeopardize important discussions concerning health and related topics. ${ }^{5}$ Many clients will feel reluctant to engage in discussions due to previous negative encounters and need additional support; dietitians can communicate this by giving clients feedback as well as intently listening to statements and concerns. $^{5}$

Weighing with care and ensuring a safe office environment go hand in hand with practicing sensitive communication. Many clients and patients have anxiety over being weighed and "asking for his or her permission to be weighed can help initiate the procedure in a respectful and sensitive manner”. ${ }^{5}$ The physical layout of the office should be considered so that every client is comfortable; this may include chairs without armrests, a location that is private and 
confidential, and reading materials that are weight-sensitive. These measures can be crucial in communicating the message that an individual's goal should be focused on making lifestyle improvements and not just weight loss. In this way, dietitians can empower clients and build confidence by communicating that small weight changes can improve health and, combined with behavioral changes, can aid in major lifestyle improvements. ${ }^{5}$

\section{Concerns, Awareness, and Interventions of Obesity Bias}

These findings among health care professionals as well as registered dietitians alone raise concerns and shed light on the need for an increase in sensitivity toward overweight and obese clients; ${ }^{5}$ this is crucial as the number of overweight and obese clients increases so that treatment practices increase in effectiveness. Increasing awareness and education on weight bias among dietetics students will counteract negative assumptions about overweight and obese patients so that treatment practices of future dietitians are not jeopardized. ${ }^{7}$ In addition to this, interventions enhancing personal appreciation of obese individuals’ experiences have shown to be beneficial in changing attitudes. ${ }^{43}$ In one study, 40 dietetics and health promotion students were asked to complete the 14-item Fat Phobia Scale, consume a calorie-restricted diet consisting of 1200-1500 calories for 1 week, and record their intake, total calories consumed per day, and thoughts about being on the diet. ${ }^{12}$ The students' journal entries indicated that they gained appreciation for people who are overweight or obese and struggling to lose weight while sticking to a restrictedcalorie diet. Some journal entry comments indicated this included “my judgmental attitude certainly got an adjustment" and "I will no longer stereotype those who are overweight" 12 The students were unanimous in learning why goals need to be realistic and feeling that completing this project will help them in dealing with future overweight and obese clients. ${ }^{12}$ This study parallels other opinions that weight management counselors and health care professionals should 
live a day in the life of their clients in order to fully comprehend the matter and empathize with their clients. $^{12,44}$

Educational interventions including videos, written materials, and role-playing exercises have shown to be beneficial in changing attitudes of medical students. In a study by Weise, Wilson, Jones, and Neises, medical students were randomly assigned to a control group or an intervention group that used videos, written materials, and role-playing scenarios in an attempt to reduce stigma toward obese patients. Prior to randomization, the majority of the students characterized obese patients as lacking self-control, lazy, and sloppy; also, the students indicated that they had an accurate understanding of the complex causes of obesity. ${ }^{45}$ Students in the intervention group showed significant improvements in attitudes and beliefs concerning obesity, and the effectiveness of the intervention was still evident 1 year later. ${ }^{45}$ Other studies have indicated that "educational programs that openly discuss bias toward obesity and present examples of prejudice in the media can reduce negative attitudes about obesity. ${ }^{3,37,45}$ This intervention method could be applied to dietetic students’ education via course readings, lectures discussing scientific research on obesity bias, and practicing sensitive communication skills through role-playing scenarios in nutrition counseling settings. ${ }^{7}$ Role-playing allows an individual to understand the situation but also to think about how he or she would respond in the discriminated person's situation. ${ }^{46}$ This is beneficial in changing individual explicit weight bias but may not resolve implicit biases that are ingrained subconsciously. Even when explicit biases are lessened, implicit biases are elicited when an individual observes cues or behaviors that are consistent with previous negative stereotypes, such as an overweight person overeating. ${ }^{46,47}$

Other studies have indicated that information highlighting the complex etiology of obesity improves negative attitudes and reduces weight bias and the accompanying stereotypes. 
${ }^{15}$ Information regarding the etiology of obesity includes biological as well as genetic contributors to weight. In addition to this, education discussing the impact of the current food environment in promoting weight gain would be very beneficial. ${ }^{48}$ One study indicated that general practitioners exhibited less bias concerning obese people and laziness when they subscribed to medical journals. ${ }^{49}$ The authors concluded that this could be because journal subscribing general practitioners were more aware of existing environmental obesity risk factors that are not controllable by patients. ${ }^{49}$

Interventions designed to increase positive perceptions about overweight and obese people can be used to improve fat phobia attitudes and perceptions that will promote a rise in client's self-esteem and increase effectiveness of treatment practices. ${ }^{3}$ The social consensus theory has shown promise in this regard in that "an individual's attitudes and beliefs are highly influenced by other's attitudes and beliefs of groups that are assumed important”, ${ }^{46,50}$ and this can attribute to the development of negative stereotypes. Several studies have documented the success of such interventions. Puhl, Schwartz, and Brownell conducted a study consisting of 3 parts to determine the effect of perceived social consensus on attitudes toward the obese population. The first part of their experiment showed that participants receiving positive consensus feedback reported more positive than negative traits about obese people. In their second study of university students $(n=55)$, consensus information was more influential and beneficial in modifying positive beliefs about obese people when coming from an in-group versus an out-group source. ${ }^{15,21}$ These findings indicate that people acquire information from those they value and identify with and that negative attitudes are more likely to change when positive attitudes arise from a valued in-group. ${ }^{15,21}$ In their final study of college students, Puhl, Schwartz, and Brownell found that not only were individual's attitudes concerning obesity 
affected by the valued in-group’s attitudes, but their beliefs concerning obesity and the causes were affected as well. ${ }^{15,21}$ Receiving positive consensus feedback was proven to be more effective in changing attitudes towards the obese population than providing information about the uncontrollable causes of obesity among other scientific evidence, which did improve attitudes to some degree. ${ }^{21}$ This finding strongly indicates that "learning about the unbiased attitudes of others can be highly influential in understanding and improving attitudes toward obese people". 21

In conclusion, evoking empathy alone toward the obese population has been unsuccessful in changing negative attitudes and stereotypes long-term. ${ }^{15,48}$ In the education setting, it is of importance for faculty members and professors to communicate positive attitudes and condemn anti-fat attitudes and for students to be motivated to identify with positive valued in-group members. ${ }^{15}$ Admired in-group members in the health care and education profession can be beneficial in advocating weight tolerance and communicating positive attributes of obese people to those in their care. ${ }^{15}$ By improving self-awareness of personal and societal bias and taking actions to reduce obesity biases and fat phobia, dietitians can play a crucial role in providing sensitive care to the overweight and obese population while assisting them in promoting healthy lifestyle changes and behaviors. 5,34 


\section{CHAPTER 3}

\section{DATA AND METHODS}

\section{Participants and Sample}

A sample of 19 dietetic students from East Tennessee State University, 25 dietetic students from Middle Tennessee State University, and 19 dietetic students from Mississippi State University completed the study. A total sample of 63 undergraduate dietetic students completed the study. Students completing the survey were juniors or seniors enrolled in Clinical Nutrition I at East Tennessee State University, Summer Practicum at Middle Tennessee State University, or Diet and Chronic Disease at Mississippi State University. A sample of 17 dietetic interns from East Tennessee State University and 8 dietetic interns from Mississippi State University completed the study. A total sample of 25 dietetic interns completed the study. A sample of 26 currently practicing registered dietitians in the east Tennessee and Northeast Mississippi area completed the study. Written informed consent to participate was obtained from the subjects, and each had the right to decline participation. Approval for this research was granted by the Institutional Review Board (IRB) through the East Tennessee State University Office of Research and Sponsored Programs.

\section{Instrumentation}

A revised version of the Fat Phobia Scale test (Appendix A) was used to determine the participants' attitudes about obesity. The survey used was adapted from the F-Scale short form used by the Rudd Center for Food Policy and Obesity at Yale University. This 14-item scale is a shortened version of the original 50-item fat phobia scale; it measures a person's attitudes regarding obese people using a scoring range from 1 to 5 . The original 50 -item fat phobia scale was validated in 1984 when the 6 distinct fat phobia subscales were determined. ${ }^{4}$ The 
participants completed the F-Scale short form one time to determine each individual's fat phobia or obesity bias.

Fat phobia scores for each participant were calculated by adding up the score for each item to get a total score. The total score was then divided by 14 to obtain an average range of 1 to 5. A score of 2.5 indicates a neutral attitude about obese people. Scores that fall below 2.5 indicate positive attitudes about obese people, whereas scores that fall above 2.5 indicate negative attitudes regarding the obese population. Based on published data, a score of 4.4 or higher indicates a high level of fat phobia or obesity bias. ${ }^{4}$

In addition to completing the F-Scale short form, participants completed the Antifat Attitudes Questionnaire (AFA) (Appendix B). The Antifat Attitudes Questionnaire is scored using a Likert-type response format with $0=$ very strongly disagree to $9=$ very strongly agree. Higher scores indicate stronger anti-fat attitudes. Participants were instructed to pick the response that best represented their attitude or belief about each statement. Statements included topics on dislike, fear of fat, and willpower. Scores for each participant were calculated by adding up each response for the 13 statements listed. This score was then compared to that of the Fat Phobia Scale for each participant to determine fat phobia, antifat attitudes, and overall obesity bias.

Finally, participants answered a questionnaire regarding demographics such as sex, age, race/ethnicity, and classification (student, intern, or registered dietitian). Participants selfreported height and weight, which was used to calculate body mass index (BMI). Students and interns answered 4 questions regarding personal and family weight history as well as friends' weight history. Registered dietitians answered questions concerning length of practice, area of dietetics practice, and current position held. They also answered 5 questions concerning 
personal, family, and friend weight history as well as how they describe themselves. These questions were included in order for the investigator to discuss possible reasons for obesity bias, antifat attitudes, and fat phobia or the lack thereof.

\section{Data Collection}

Questionnaires were given to and collected from the students, interns, and registered dietitians during the summer and fall of 2012. In order to maintain anonymity, the researcher advised all participants to not include their name or any other identifying information on the scale or questionnaire. The principal investigator will keep all of the completed questionnaires in a secure and confidential location for 5 years. After the 5 years expires, the principal investigator will shred and dispose of the documents.

\section{Research Questions}

The following research questions were analyzed:

1) Does obesity bias improve as an individual moves through the dietetics profession or does it digress as one interacts with the obese population?

2) Are overweight or obese registered dietitians less likely to have obesity bias than practicing dietitians who are maintaining a healthy weight?

\section{Statistical Analysis}

The Statistical Package for Social Sciences (SPSS) Windows computer software program (Version 19.0, 2011, PSS, Inc., Chicago, IL) was used to analyze the collected data. Subjects were grouped according to classification within the dietetic field; group 1 was undergraduate DPD students, group 2 was dietetic interns, and group 3 was practicing registered dietitians.

Descriptive statistics and frequencies were used to report demographic questions for the 3 groups; these questions covered BMI, gender, age, race, family history of obesity, personal 
history of obesity, presence of obese friends, and description of close friends. In addition, frequencies were used to report demographics specific to practicing registered dietitians, which included state, years of practice, place of work, dietetic practice area, and description of self.

The Pearson $r$ correlation coefficient was used to determine the strength and direction of the relationship between 2 variables within 1 group of participants. This test was used to determine the relationship between a dietitian’s BMI and his/her Anti-fat Attitude Questionnaire score and his/her Fat Phobia Scale score. The dietitian’s BMIs were categorized into 2 groups: healthy BMI and overweight BMI. Then 2 groups were used to determine whether or not overweight or obese dietitians are less likely to have obesity bias than practicing dietitians who are maintaining a healthy weight based upon attitudes about obesity and the relationship between BMI and degree of fat phobia present.

Multivariate analysis of variance (MANOVA) tests were performed to compare Anti-fat Attitude Questionnaire scores between undergraduate DPD students, dietetic interns, and practicing registered dietitians to determine whether or not obesity bias improves as an individual moves through the dietetics profession or digresses as one interacts with the obese population. This test was also used to compare Fat-phobia Scale scores among the 3 groups for the same purposes previously mentioned. 


\section{CHAPTER 4}

\section{RESULTS AND DISCUSSION}

Demographic Data

The total sample consisted of 114 participants. Of these participants, 63 were undergraduate students, 25 were dietetic interns, and 26 were practicing registered dietitians. Of the total participants, only 13 of the 114 (11.4\%) were male. Among the 3 groups, 9 of 63 (14.3\%) undergraduate students, 0 of 25 dietetic interns, and 4 of 26 (15.4\%) dietitians were male. Among the undergraduate students, the age ranged from 20 to 49 years with the majority being 20 to 29 (92.1\%) years of age. Among the dietetic interns, ages ranged from 20 to 39 years with the majority being 20 to 29 (88\%) years of age. Among the practicing registered dietitians, the age ranged from 20 to 69 years of age with the majority being 40 to 49 (26.9\%) years of age. In terms of race/ethnicity, 107 of the 114 (94\%) participants were white, 4 of the 114 (3.5\%) were African American, and 3 of the 114 (2.5\%) were categorized as Hispanic or "other” (Table 2).

Height and weight were self-reported and used to calculate Body Mass Index by the equation weight [lbs]/height [inches] ${ }^{2 *} 703$. All BMI scores were classified as either normal (18.5-24.9), overweight (25.0- 29.9), and obese (30.0 >). Of the total sample, 19 of 114 (16.7\%) were calculated to be overweight and 5 of 114 (4.4\%) were calculated to be obese. Participants reported family and personal history of overweight and obesity. Of the total sample, 51 of 114 (45\%) participants reported family history of overweight and obesity while only 25 of the 114 (22\%) participants reported a personal history of overweight and obesity. Of the total sample, 99 out of 114 (87\%) reported having overweight or obese friends; however, only 8 of 114 (7\%) participants reported having close friends who were overweight or obese (Table 2). 
Table 2. Demographic Characteristics

\begin{tabular}{|c|c|c|c|}
\hline Variables & Undergraduate DPD & Dietetic Interns & Practicing Dietitians \\
\hline & $\mathrm{n}(\%)$ & $\mathrm{n}(\%)$ & $\mathrm{n}(\%)$ \\
\hline $\begin{array}{l}\text { Body Mass Index } \\
18.5-24.9 \\
25.0-29.9 \\
30.0>\end{array}$ & $\begin{array}{c}46(73 \%) \\
14(22.2 \%) \\
3(4.8 \%)\end{array}$ & $\begin{array}{c}24(96 \%) \\
1(4 \%) \\
0(0 \%)\end{array}$ & $\begin{array}{c}20(76.9 \%) \\
4(15.4 \%) \\
2(7.7 \%)\end{array}$ \\
\hline $\begin{array}{l}\text { Gender } \\
\text { Male } \\
\text { Female }\end{array}$ & $\begin{array}{c}9(14.3 \%) \\
54(85.7 \%)\end{array}$ & $\begin{array}{c}25(100 \%) \\
0(0 \%)\end{array}$ & $\begin{array}{c}4(15.4 \%) \\
22(84.6 \%)\end{array}$ \\
\hline $\begin{array}{l}\text { Age } \\
20-29 \text { y } \\
30-39 \text { y } \\
40-49 \text { y } \\
50-59 \text { y } \\
60-69 \text { y }\end{array}$ & $\begin{array}{c}58(92.1 \%) \\
4(6.3 \%) \\
1(1.6 \%) \\
0(0 \%) \\
0(0 \%)\end{array}$ & $\begin{array}{c}22(88 \%) \\
3(12 \%) \\
0(0 \%) \\
0(0 \%) \\
0(0 \%)\end{array}$ & $\begin{array}{l}4(15.4 \%) \\
6(23.1 \%) \\
7(26.9 \%) \\
6(23.1 \%) \\
3(11.5 \%)\end{array}$ \\
\hline $\begin{array}{l}\text { Race } \\
\text { White } \\
\text { African American } \\
\text { Hispanic } \\
\text { Other }\end{array}$ & $\begin{array}{c}57(90.5 \%) \\
4(6.3 \%) \\
1(1.6 \%) \\
1(1.6 \%)\end{array}$ & $\begin{array}{c}25(100 \%) \\
0(0 \%) \\
0(0 \%) \\
0(0 \%)\end{array}$ & $\begin{array}{c}25(96.2 \%) \\
0(0 \%) \\
0(0 \%) \\
1(3.8 \%)\end{array}$ \\
\hline $\begin{array}{l}\text { Family History of } \\
\text { Overweight/Obesity } \\
\text { Yes } \\
\text { No }\end{array}$ & $\begin{array}{l}30(47.6 \%) \\
33(52.4 \%)\end{array}$ & $\begin{array}{c}8(32 \%) \\
17(68 \%)\end{array}$ & $\begin{array}{l}13(50 \%) \\
13(50 \%)\end{array}$ \\
\hline $\begin{array}{l}\text { Personal History of } \\
\text { Overweight/Obesity } \\
\text { Yes } \\
\text { No }\end{array}$ & $\begin{array}{l}14(22.2 \%) \\
49(77.8 \%)\end{array}$ & $\begin{array}{c}3(12 \%) \\
22(88 \%)\end{array}$ & $\begin{array}{c}8(30.8 \%) \\
18(69.2 \%)\end{array}$ \\
\hline $\begin{array}{l}\text { Overweight/Obese } \\
\text { Friends } \\
\text { Yes } \\
\text { No } \\
\end{array}$ & $\begin{array}{l}53(84.1 \%) \\
10(15.9 \%)\end{array}$ & $\begin{array}{c}22(88 \%) \\
3(12 \%)\end{array}$ & $\begin{array}{c}24(92.3 \%) \\
2(7.7 \%) \\
\end{array}$ \\
\hline $\begin{array}{l}\text { Description of Close } \\
\text { Friends } \\
\text { Underweight } \\
\text { Normal } \\
\text { Overweight/Obese }\end{array}$ & $\begin{array}{c}1(1.6 \%) \\
59(93.7 \%) \\
3(4.8 \%)\end{array}$ & $\begin{array}{c}0(0 \%) \\
25(100 \%) \\
0(0 \%)\end{array}$ & $\begin{array}{c}0(0 \%) \\
21(80.8 \%) \\
5(19.2 \%)\end{array}$ \\
\hline
\end{tabular}

\section{Demographics Specific to Practicing Registered Dietitians}

The survey administered to practicing registered dietitians included 6 questions that were applicable only to their group. The majority of the dietitians surveyed had been in practice for 1 to 10 years (42.3\%) or 11 to 20 years (30.8\%). As far as the work place is concerned, 11 out of 26 (42.3\%) dietitians were employed by a university in Tennessee or Mississippi and 9 out of 26 
(30.8\%) were employed by hospitals in the same area. Therefore, 38.5\% and 26.9\% of the dietitians surveyed were included in education and clinical dietetic practice areas, respectively. These participants were asked to describe themselves as either underweight, normal weight, or overweight/obese. Of the 26 participants, 20 (76.9\%) described themselves as normal weight while 6 (23.1\%) described themselves as overweight or obese (Table 3).

Table 3. Demographics Specific to Registered Dietitians

\begin{tabular}{|l|c|}
\hline \multicolumn{1}{|c|}{ Variables } & Practicing Dietitians \\
\hline State & $\mathrm{n}(\%)$ \\
Tennessee & $19(73.1 \%)$ \\
Mississippi & $7(26.9 \%)$ \\
\hline Years of Practice & \\
$1-10 \mathrm{y}$ & $11(42.3 \%)$ \\
$11-20 \mathrm{y}$ & $8(30.8 \%)$ \\
$21-30$ y & $5(19.2 \%)$ \\
$31-40$ y & $2(7.7 \%)$ \\
\hline Workplace & \\
University & $11(42.3 \%)$ \\
Hospital & $9(34.6 \%)$ \\
Health Department & $4(15.4 \%)$ \\
Other & $2(7.7 \%)$ \\
\hline Dietetic Practice Area & $10(38.5 \%)$ \\
Education & $7(26.9 \%)$ \\
Clinical & $4(15.4 \%)$ \\
Public Health & $5(19.2 \%)$ \\
Other & \\
\hline Description of Self & $0(0 \%)$ \\
Underweight & $20(76.9 \%)$ \\
Normal & $6(23.1 \%)$ \\
Overweight/Obese & \\
\hline
\end{tabular}




\section{The Relationship Between BMI and Fat Phobia Scores}

Students, interns, and dietitians completed 2 surveys to determine the degree of fat phobia present via the Fat Phobia Survey and the Anti-fat Attitude Survey. The relationship between nutrition students with a healthy BMI $(\mathrm{n}=46)$ and their Fat Phobia score was direct and weak $(r=0.024)$. The relationship between nutrition students with a healthy BMI $(n=44)$ and their Anti-fat Attitude score was inverse and weak $(r=-0.145)$. The relationship between nutrition students with an overweight/obese BMI (n=17) and their Fat Phobia scores was weak and direct $(r=0.138)$ while there was a moderate and inverse relationship with their Anti-fat Attitude survey $(r=-0.319)$. The relationship between interns with a healthy BMI $(\mathrm{n}=24)$ and their Fat Phobia scores was weak and inverse $(r=-0.128)$ while their Anti-fat Attitude surveys were weak and direct $(r=0.201)$. The relationship between interns with an overweight or obese BMI and their Fat Phobia and Anti-fat Attitude scores could not be computed because at least one of the variables was constant in that only 1 out of 25 interns was categorized as having an overweight or obese BMI. The relationship between dietitians with a healthy BMI $(\mathrm{n}=20)$ and their Fat Phobia scores $(r=0.130)$ and Anti-fat Attitude scores $(r=0.103)$ were weak and direct. The relationship between dietitians with an overweight or obese BMI $(n=6)$ and their Fat Phobia scores was weak and direct $(r=0.010)$. However, the relationship between their Anti-fat Attitude scores was weak and indirect ( $r=-0.072)$ indicating that if one was overweight he/she was likely to be less biased than those with a lower BMI (Table 4).

In a study, individuals of a healthy weight have been found to be less tolerant of overweight people. ${ }^{42}$ Some research has found that those of lower BMI values have more negative attitudes about obesity ${ }^{42}$, whereas other research indicates no effect of BMI on attitudes 
concerning obesity. ${ }^{7,11}$ Also, younger individuals have shown greater weight biases than older adults. $^{43}$

Table 4. Correlation Coefficients from Two Surveys

\begin{tabular}{|l|c|c|}
\hline \multicolumn{1}{|c|}{ Variable } & Fat Phobia Survey & Anti-fat Attitude Survey \\
\hline & $\mathrm{r}$ & $\mathrm{r}$ \\
& $\mathrm{n}$ & $\mathrm{n}$ \\
& $\mathrm{p}$ value & $\mathrm{p}$ value \\
\hline Students with Healthy BMI & 0.024 & -0.145 \\
& $(46)$ & $(44)$ \\
& 0.874 & 0.348 \\
\hline Students with Overweight/Obese BMI & 0.138 & -0.319 \\
& $(17)$ & $(16)$ \\
& 0.597 & 0.228 \\
\hline Interns with Healthy BMI & -0.128 & 0.201 \\
& $(24)$ & $(24)$ \\
& 0.552 & 0.347 \\
\hline Interns with Overweight/Obese BMI & $\mathrm{NA} *$ & $\mathrm{NA}$ \\
\hline RDs with Healthy BMI & 0.130 & 0.103 \\
& $(20)$ & $(20)$ \\
& 0.583 & 0.666 \\
\hline RDs with Overweight/Obese BMI & 0.010 & -0.072 \\
& $(5)$ & $(6)$ \\
& 0.987 & 0.892 \\
\hline
\end{tabular}

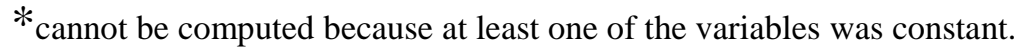

\section{Comparisons of Fat Phobia Scores Among Students, Interns, and Dietitians}

Table 5 demonstrates the differences between mean Fat Phobia scores for undergraduate DPD students, dietetic interns, and practicing registered dietitians. Undergraduate DPD students had a mean score of $3.4 \pm 0.98$ for the Fat Phobia scale short form that consisted of 14-items that measured a person's attitudes about obese people using a scoring range from 1 to 5 . The mean score for the dietetic interns was $3.6 \pm 0.58$ while the mean score for registered dietitians was 3.4 \pm 0.81 . These results indicate that obesity bias was present among each group but decreased slightly from dietetic interns to registered dietitians; however, it was not a significant decrease 
between the 2 groups. The mean score for the total sample was $3.5 \pm 0.86$, which indicates obesity bias because it lies above 2.5 , which is a neutral score.

The differences between Anti-fat Attitude scores among undergraduate DPD students, dietetic interns, and practicing registered dietitians were also noted in Table 5. The Anti-fat Attitude survey tested the participants' response to statements on dislike, fear of fat, and willpower to determine their attitudes or beliefs about posed statements. Higher scores indicated stronger anti-fat attitudes. The mean score for undergraduate students was $51.9 \pm 20.3$ indicating that there was not "more" or "less" fat phobia. The dietetic interns had a mean score of $46.2 \pm$ 18.7 indicating less obesity bias than undergraduate students but not a significant decrease. The mean score for practicing registered dietitians was $43.5 \pm 18.6$, which indicated a decrease in obesity bias as one moves through the dietetic profession but not a significant decrease between the three groups. The mean scores for each group fell within the middle range for both obesity bias tests with the scores decreasing from students to interns to dietitians. This indicates less fat phobia and obesity bias over time but no significance differences were found between the three groups.

Table 5. Means \pm SD of Anti-fat Attitude Questionnaire and Fat Phobia Scale to Determine Weight Bias among Undergraduate DPD Students, Dietetic Interns, and Practicing Registered Dietitians

\begin{tabular}{|l|c|c|c|c|}
\hline & $\begin{array}{c}\text { Undergrad DPD } \\
\text { Mean } \pm \text { SD }\end{array}$ & $\begin{array}{c}\text { Dietetic Interns } \\
\text { Mean } \pm \text { SD }\end{array}$ & $\begin{array}{c}\text { Practicing RDs } \\
\text { Mean } \pm \text { SD }\end{array}$ & $\begin{array}{c}\text { Total } \\
\text { Mean } \pm \text { SD }\end{array}$ \\
\hline Anti-fat Attitude $^{\mathbf{a}}$ & $51.9 \pm 20.3$ & $46.2 \pm 18.7$ & $43.5 \pm 18.6$ & $48.7 \pm 19.8$ \\
\hline Fat Phobia Scale $^{\mathbf{b}}$ & $3.4 \pm 0.98$ & $3.6 \pm 0.58$ & $3.4 \pm 0.81$ & $3.5 \pm 0.86$ \\
\hline
\end{tabular}

${ }^{\mathrm{a}}=0-117$ possible score

${ }^{\mathrm{b}}=1-5$ where $1=$ strongly agree; $2=$ agree; $3=$ neutral; $4=$ disagree; $5=$ strongly disagree

There was no significant difference in fat phobia scores found between undergraduate dietetics students, dietetic interns, and practicing registered dietitians. Moreover, the level of fat 
phobia of the 3 groups is similar to what has been reported previously for dietetics students and professionals in that fat phobia is present amongst the population. ${ }^{77}$ Studies have reported mean fat phobia scores of 3.66 and $3.69^{37}$, and $3.7^{7}$ comparable to 3.43 for undergraduate dietetics students, 3.65 for dietetic interns, and 3.40 for practicing registered dietitians. These findings suggest the possibility of obesity bias improving as an individual moves through the dietetics profession but not significantly. Even though there is a slight improvement with bias, a level of fat phobia was still present among the practicing registered dietitians as evidenced by a mean score of 3.40 with 2.5 representing neutral feelings on the fat phobia scale. However, the decrease in mean fat phobia scores between students and dietitians indicates that attitudes may become less biased after interactions with the obese population in a clinical practice setting. Those working closely with clients who struggle with weight management may see a change in their ideas about overweight and obesity.

In addition, there was no significant difference in anti-fat attitude scores found between undergraduate dietetics students, dietetic interns, and practicing registered dietitians. The neutral range for the anti-fat attitudes questionnaire falls between 55 and 65, with higher scores indicating an increased level of obesity bias and lower scores indicating a decreased level of obesity bias. The results for the 3 groups were lower than the median range indicating a lesser amount of obesity bias when compared to fat phobia scores of the same sample. In comparison to the fat phobia scores, anti-fat attitude scores improved in correlation with the current stage of the dietetics profession an individual was in as evidenced by the following mean scores: 51.92 for undergraduate dietetics students, 46.24 for dietetic interns and 43.46 for practicing registered dietitians. This is indicative of the potential for obesity bias to improve as a dietetics professional 
works with clients or patients who struggle with weight management despite attempts and willingness to lose weight and maintain weight loss.

Findings suggest that an individual's BMI may be correlated to levels of obesity bias whether a dietetics student, dietetic intern, or registered dietitian; however, these findings were not significant. In relation to this, findings suggest that overweight or obese registered dietitians are less likely to have obesity bias than practicing registered dietitians who are maintaining a healthy weight when asked specific questions pertaining to the obese population. However, when asked to complete a survey about the obese population and adjectives commonly used to describe them, overweight dietitians scored in close proximity to those at a healthy weight indicating obesity bias among the entire sample of dietitians. This finding indicates that obesity bias may be less apparent when participants are asked to respond to a sentence pertaining to the overweight population because there is more time to think about one's answer. In contrast, asking one to check adjectives he or she believes pertains to the obese population does not allow for secondguessing of answers and provides a better indication of one’s true level of obesity bias.

The negative correlation between BMI, fat phobia, and anti-fat attitude scores fell close to the moderate correlation range of .25 to .49 . An increase in the sample size would be beneficial, but it would not cause an increase in the correlation between BMI and survey scores. This would further signify that as an individual's BMI decreases, his/her fat phobia and level obesity bias increases. In contrast, as an individual's BMI increases, his/her fat phobia and level of obesity bias decreases. This has been found to be true in a similar study in which a negative correlation of BMI and fat phobia was found when these 2 factors were measured. That particular study indicated that healthy weight individuals have more negative attitudes towards obesity than overweight or obese individuals. ${ }^{42}$ 


\section{CHAPTER 5}

\section{CONCLUSIONS AND IMPLICATIONS}

This study was designed to determine whether or not obesity bias improves as an individual moves through the dietetics profession and interacts more with the overweight and obese population. The secondary purpose of this study was to determine whether or not overweight or obese dietitians are less likely to have obesity bias than practicing registered dietitians who maintain a healthy weight. Due to various factors, no significant change between groups was found; however, there was a slight decrease in overall negative attitudes about obesity as evidenced by a slight decrease in fat phobia and anti-fat attitude mean scores between undergraduate dietetic students, dietetic interns, and practicing registered dietitians. This is promising for the dietetics profession as it pertains to patient care, specifically the care of overweight and obese patients and clients. In addition to this, overweight and obese registered dietitians are not exempt from exhibiting obesity bias towards clients, even though levels of bias may be less than those dietitians of a healthy weight.

The inclusion of courses that focus on acceptance of the overweight and obese population as well as weight bias information should be integrated into the undergraduate and graduate level dietetics curricula to combat weight discrimination. However, additional data need to be collected to determine appropriate changes in current dietetics programs that need to be initiated. Increasing awareness and education on weight bias among students will counteract negative assumptions about overweight and obese patients so that treatment practices of future dietitians are not jeopardized. ${ }^{7}$ Educational interventions including videos, written materials, and roleplaying exercises can be beneficial in changing attitudes of dietetics students as evidenced by a similar study conducted on medical students. ${ }^{45}$ 
Limitations in this study included that the sample size for interns and dietitians was small and was sampled only from East Tennessee and Northeast Mississippi. Small sample size may have influenced the lack of significant differences found in the results. Use discretion when interpreting results. The entire sample was primarily comprised of white women. The findings cannot be generalized to male students, interns, and dietitians or individuals of varied racial and ethnic backgrounds. The data gathered in this study were self-reported by each participant. Therefore, the honesty of the answers may have influenced the results. Also, the subjects in the study are from specific areas in 2 different states- Middle and East Tennessee and Northeast Mississippi- which limits the ability to generalize the results of the study. Finally, the number of participants for the 3 groups differentiated and, therefore, did not allow for a complete comparison between groups. Discretion should be taken when interpreting the results in which the groups were compared.

A more diverse sample group would be beneficial in determining fat phobia among groups of ethnicity, as weight stigma may be impacted by culture. In relation to this, a broader sample group geographically would also be beneficial in determining obesity bias among different states as well as different compass points in the United States. For example, a broader sample would shed light on different levels of obesity bias among the North and the South or the East and the West parts of the United States. Also, males may have differing attitudes toward obesity; therefore, larger studies including a significant male population is needed. Lastly, intervention studies addressing various methods to lessen obesity bias and its impact on negative attitudes towards obesity are needed to aid in development of educational programs that address obesity bias and its impact on patient and client care. 
It is crucial that awareness is brought to the dietetics profession concerning obesity bias and the affects it can have on patient and client care. This is especially important because the health care system and its providers are not exempt from instigating obesity bias, yet are responsible for counseling overweight and obese individuals, helping them set realistic goals, and supporting them as they strive to make lifestyle changes. Interventions that question negative weight-related stigmas and promote sensitivity and empathy may be useful in lessening obesity bias among dietetic students, dietetic interns, and dietitians. In turn, this may positively impact the treatment and care of overweight and obese patients and clients.

Undergraduate and graduate level dietetics programs need to address weight discrimination and the affect it has on client and patient care. Due to the obesity epidemic in the United States, dietetic students and interns who are better prepared for providing weight management treatment will improve the practice of dietetics as well as enhance the health and well-being of their clients and patients. Continuing education for practicing registered dietitians may be beneficial in addressing the issues of weight discrimination, obesity bias, fat phobia, and the negative attitudes that accompany these biases. As the national obesity epidemic continues to rise with 68\% of Americans falling within the overweight BMI category and 34\% being classified as obese, immediate awareness of such biases is crucial in improving weight management health care for patients and clients. By improving self-awareness of personal bias and taking actions to reduce obesity bias, dietitians and soon-to-be dietitians can play a crucial role in providing sensitive care to overweight and obese clients while assisting them in promoting healthy lifestyle changes and behaviors. ${ }^{5}$ 


\section{REFERENCES}

1. Centers for Disease Control and Prevention. Obesity and overweight. Available at http://www.cdc.gov/nchs/fastats/overwt.htm. Updated: May 2012. Accessed July 2012.

2. Centers for Disease Control and Prevention. Health consequences. Available at http://www.cdc.gov/obesity/causes/health.html. Updated: May 2012. Accessed July 2012.

3. Robinson BE, Bacon JG, O'Reilly J. Fat phobia: measuring, understanding, and changing anti-fat attitudes. International Journal of Eating Disorders. 1993; 14(4): 467-480.

4. Bacon JG, Scheltema KE, Robinson BE. Fat phobia scale revisited: the short form. International Journal of Obesity. 2001; 25: 252-257.

5. Puhl RM. Prejudice and Discrimination. In: Nonas CA, Foster GD. Managing Obesity: A Clinical Guide. $2^{\text {nd }}$ ed. 14: 231-237.

6. Yale University Rudd Center on Food Policy and Obesity. Weight bias and quality of life. 2009; 103.

7. Puhl R, Wharton C, Heuer C. Weight bias among dietetic students: implications for treatment practices. J Am Diet Assoc. 2009; 109: 438-444.

8. McArthur L, Ross J. Attitudes of registered dietitians toward personal overweight and overweight clients. J Am Diet Assoc. 1997; 97: 63-66.

9. Whitney E, Rolfes SR. Energy balance and body composition. In: Understanding Nutrition. $11^{\text {th }}$ ed. Thomson Wadsworth. Belmont, CA; 2008. 248-270.

10. Centers for Disease Control and Prevention. Defining overweight and obesity. Available at http://www.cdc.gov/obesity/defining.html. Updated May 2012. Accessed July 2012.

11. Latner JD, Stunkard AJ, Wilson GT. Stigmatized students: age, sex, and ethnicity effects in the stigmatization of obesity. Obesity Research. 2005; 13(7): 1226-1231.

12. Cotugna N, Mallick A. Following a calorie-restricted diet may help in reducing healthcare students' fat-phobia. J Community Health. 2010; 35: 321-324.

13. Carr D, Friedman MA. Is obesity stigmatizing? Body weight, perceived discrimination, and psychological well-being in the United States. J Health Soc Behav. 2005; 46 (3): 244-259. 
14. Hansson LM, Naslund E, Rasmussen F. Perceived discrimination among men and women with normal weight and obesity. A population-based study from Sweden. Scandinavian $J$ Pub Health. 2010; 38: 587-596.

15. Puhl RM, Schwartz MB, Brownell KD. Impact of perceived consensus on stereotypes about obese people: a new approach for reducing bias. Health Psychology. 2005; 24 (5): 517-525.

16. Crandall CS, D’Anello S, Sakalli N, Lazarus E, Wieczorkowska G, Feather NT. An attribution-value model of prejudice: anti-fat attitudes in six nations. Personality and Social Psychology Bulletin. 2001; 27: 30-37.

17. Crandall CS, Schiffhauer KL. Anti-fat prejudice: beliefs, values, and American culture. Obes Res. 1998; 6: 458-460.

18. Puhl RM, Brownell KD. Psychosocial origins of obesity stigma: toward changing a powerful and pervasive bias. Obesity Reviews. 2003; 4: 213-227.

19. Crandall CS. Prejudice against fat people: ideology and self-interest. JPSP. 1994; 66: 882-894.

20. Crandall CS, Cohen C. The personality of the stigmatizer. Cultural world view, conventionalism, and self-esteem. J Res Pers. 1994; 28: 461-480.

21. Brownell K, Puhl R. Stigma and discrimination in weight management and obesity. The Permanente Journal. 2003; 7 (3): 21- 23.

22. Li W, Rukavina P. A review of coping mechanisms against obesity bias in physical activity/education settings. Obesity Reviews. 2009; 10: 87-95.

23. Williams DR, Neighbors HW, Jackson JS. Racial/ethnic discrimination and health: findings from community studies. Am J Public Health. 2003; 93 (2): 200-208.

24. Myers A, Rosen JC. Obesity stigmatization and coping: relation to mental health symptoms, body image, and self-esteem. Int J Obes. 1999; 23: 221-230.

25. Puhl R, Brownell KD. Ways of coping with obesity stigma: review and conceptual analysis. Eat Behav. 2003; 4: 53-78.

26. Garner DM, Olmsted MP, Bohr Y, Garfinkel PE. The Eating Attitudes Test: psychometric features and clinical correlates. Psychol Med. 1982; 12: 871-878. 
27. Jackson TD, Grilo CM, Masheb RM. Teasing history, onset of obesity, current eating disorder psychopathology, body dissatisfaction, and psychological functioning in binge eating disorder. Obes Res. 2002; 8: 451-458.

28. Faith MS, Leone MA, Ayers TS, Heo M, Pietrobelli A. Weight criticism during physical activity, coping skills, and reported physical activity in children. Pediatrics. 2002; 110: e23.

29. Storch EA, Milsom VA, DeBraganza N, Lewin AB, Geffken GR, Silverstein JH. Peer victimization, psychosocial adjustment, and physical activity in overweight and at-riskfor-overweight youth. J Pediatr Psychol. 2007; 32: 80-89.

30. Crocker J, Cornwell B, Major B. The stigma of overweight: affective consequences and attributional ambiguity. J Pers Soc Psychol. 1993; 64: 60-70.

31. Fuller ML, Groce SB. Obese women's responses to appearance norms. Free Inq Creat Sociol. 1991; 19: 167-174.

32. Muennig P, Jia H, Lee R, Lubetkin E. I think therefore I am: perceived ideal weight as a determinant of health. Am J Public Health. 2008; 98 (3) 501-506.

33. Gee GC, Ro A, Gavin A, Takeuchi DT. Disentangling the effects of racial and weight discrimination on body mass index and obesity among Asian Americans. Am J Public Health. 2008; 98 (3): 493-500.

34. Puhl R, Brownell KD. Bias, discrimination, and obesity. Obes Res. 2001; 9: 788-805.

35. Amy NK, Aalbord A, Lyons P, Keranen L. Barriers to routine gynecological cancer screening for white and African-American obese women. Int J Obes Relat Metab Disord. 2006; 30: 147-155.

36. Drury CA, Louis M. Exploring the association between body weight, stigma of obesity, and health care avoidance. J Am Acad Nurse Pract. 2002; 14: 554-561.

37. Berryman DE, Dubale GM, Manchester DS, Mittelstaedt R. Dietetics students possess negative attitudes toward obesity similar to nondietetics students. J Am Diet Assoc. 2006; 106: 1678-1682.

38. Hoppe R, Ogden J. Practice nurses' beliefs about obesity and weight related interventions in primary care. Int J Obes Relat Metab Disord. 1997; 21: 141-146. 
39. Maroney D, Golud S. Nurse's attitudes toward obese persons and certain ethnic groups. Percept Mot Skills. 1992; 75: 387-391.

40. DeJong W. The stigma of obesity: the consequences of naïve assumptions concerning the causes of physical deviance. J Health Soc Behav. 1980; 21: 75-87.

41. Harvey EL, Summerbell CD, Kirk SF, Hill AJ. Dietitians' views of overweight and obese people and reported management practices. J Hum Nutr Diet. 2002; 15: 331-347.

42. Oberrieder H, Walker R, Monroe D, Adeyanju M. Attitudes of dietetics students and registered dietitians towards obesity. J Am Diet Assoc. 1995; 95: 914-919.

43. Schwartz MB, Chambliss HO, Brownell KD, Blair SN, Billington C. Weight bias among health professionals specializing in obesity. Obes Res. 2003; 11 (9): 1033-1039.

44. Wadsworth LA, Thompson AM. Media literacy: a critical role for dietetic practice. Canadian J Diet Pract and Res. 2005; 66 (1): 30-36.

45. Wiese HJ, Wilson JF, Jones RA, Neises M. Obesity stigma reduction in medical students. Int J Obes Relat Metab Disord. 1992; 16 (11): 859-868.

46. Rukavina PB, Li W. School physical activity interventions: do not forget about obesity bias. Obesity Reviews. 2007; 1-9.

47. Blair IV, Ma JE, Lenton AP. Imaging stereotypes away: the moderation of implicit stereotypes through mental imagery. J Pers Soc Psychol. 2001; 81: 828-841.

48. Teachman BA, Brownell KD. Implicit anti-fat among health professionals: is anyone immune? Int J Obes. 2001; 25 (10): 1525-1531.

49. Bocquier A, Verger P, Basdevant A, Andreotti G, Baretge J, Villani P, Paraponaris A. Overweight and obesity: knowledge, attitudes, and practices of general practitioners in France. Obes Res. 2005; 13 (4): 787-795.

50. Levine JM, Resnick LB, Higgins ET. Social foundations of cognition. Annu Rev Psychol. 1993; 44: 585-612. 


\section{APPENDICES}

APPENDIX A: Institutional Review Board Letter of Approval

East Tennessee State University

Office for the Protection of Human Research Subjects • Box $70565 \bullet$ Johnson City, TN 376141707

Phone: (423) 439-6053 Fax: (423) 439-6060

\section{IRB APPROVAL - Initial Exempt}

June 15, 2012

Ms. Michelle Lee

Dept of Allied Health

P.O. Box 70690

Johnson City, TN 37614

RE: Comparison of Obesity Bias, Attitudes, and Beliefs Among Undergraduate Dietetic Students, Dietetic Interns, and Practicing Registered Dietitians.

IRB\#: c0612.7e

ORSPA\#:

On June 14, 2012, an exempt approval was granted in accordance with 45 CFR 46. 101(b)(2). It is understood this project will be conducted in full accordance with all applicable sections of the IRB Policies. No continuing review is required. The exempt approval will be reported to the convened board on the next agenda.

- New Protocol Submission (xform - no conflict identified); CV; Permission from MSU and MTSU; RD Survey; Student \& Intern Survey; Informed Consent

Unanticipated Problems Involving Risks to Subjects or Others must be reported to the IRB (and VA R\&D if applicable) within 10 working days.

Proposed changes in approved research cannot be initiated without IRB review and approval. The only exception to this rule is that a change can be made prior to IRB approval when necessary to eliminate apparent immediate hazards to the research subjects [21 CFR 56.108 (a)(4)]. In such a case, the IRB must be promptly informed of the change following its implementation (within 10 working days) on Form 109 (www.etsu.edu/irb). The IRB will review the change to determine that it is consistent with ensuring the subject's continued welfare.

Sincerely,

Chris Ayres, Chair

ETSU Campus IRB 


\section{APPENDIX B: Survey Documents for Students and Interns}

\section{Comparison of Obesity Bias, Attitudes, and Beliefs Among Undergraduate Dietetic Students, Dietetic Interns, and Practicing Registered Dietitians}

Thank you for supporting our research by completing this survey. We realize that your time is valuable and we appreciate your participation. The purpose of this research is to compare attitudes, beliefs, and bias concerning obesity among undergraduate dietetic students, dietetic interns, and practicing registered dietitians in Middle Tennessee, East Tennessee, and Northeast Mississippi. The procedures, which will involve you as a research subject, include completing this survey that will take about 5 minutes of your time. Participation in this research experiment is voluntary. You may refuse to participate. You can quit at any time. If you quite or refuse to participate, the benefits or treatment to which you are otherwise entitled will not be affected. You may quit by contacting Sarah Welborn at welborns@goldmail.etsu.edu or Dr. Michelle Lee at 423-439-7524 or leeml2@etsu.edu. For questions, comments or concerns, please contact Sarah Welborn at welborns@goldmail.etsu.edu or Dr. Michelle Lee at 423-439-7524 or leeml2@etsu.edu. You may contact the ETSU Institutional Review Board at 423-439-6054 for any questions you may have about your rights as a research subject. By continuing to answer the questions in the rest of the survey, you confirm that you have read this document.

\section{Demographics}

Height: (feet and inches)

Weight: (pounds)

Sex: Male Female

Age:

Race/ethnicity: White African American Hispanic Other

Circle the best answer for the following:

1. I am a (an):

a. Undergraduate dietetic student

b. Dietetic intern

2. I attend:

a. Middle Tennessee State University

b. East Tennessee State University

c. Mississippi State University

3. Do you have a family history of overweight/obesity? Yes No

4. Do you have a personal history of overweight/obesity? Yes No

5. Have you ever had a close friend who was overweight or obese? Yes No

6. How would you describe most of your closest friends?

a. Underweight 
b. Normal/Average Weight

c. Overweight

Antifat Attitudes Questionnaire (AFA) ${ }^{1}$

The AFA is scored using a Likert-type response format ( 0 = very strongly disagree; $9=$ very strongly agree). Higher scores indicate stronger anti-fat attitudes. Pick the response that best represents your attitude or belief.

$\begin{array}{llllllll}0 & \text { very strongly disagree } & 3 & \text { somewhat disagree } & 6 & \text { somewhat agree } & 9 & \text { very strongly agree } \\ 1 & \text { strongly disagree } & 4 & \text { disagree } & 7 & \text { moderately agree } & & \\ 2 & \text { moderately disagree } & 5 & \text { agree } & 8 & \text { strongly agree } & \end{array}$

Dislike

1. I really don’t like fat people much.

$\begin{array}{llllllllll}0 & 1 & 2 & 3 & 4 & 5 & 6 & 7 & 8 & 9\end{array}$

2. I don't have many friends that are fat.

$\begin{array}{llllllllll}0 & 1 & 2 & 3 & 4 & 5 & 6 & 7 & 8 & 9\end{array}$

3. I tend to think that people who are overweight are a little untrustworthy.

$\begin{array}{llllllllll}0 & 1 & 2 & 3 & 4 & 5 & 6 & 7 & 8 & 9\end{array}$

4. Although some fat people are surely smart, in general, I think they tend not to be quite as bright as normal weight people.

$\begin{array}{llllllllll}0 & 1 & 2 & 3 & 4 & 5 & 6 & 7 & 8 & 9\end{array}$

5. I have a hard time taking fat people too seriously.

$\begin{array}{llllllllll}0 & 1 & 2 & 3 & 4 & 5 & 6 & 7 & 8 & 9\end{array}$

6. Fat people make me somewhat uncomfortable.

$\begin{array}{llllllllll}0 & 1 & 2 & 3 & 4 & 5 & 6 & 7 & 8 & 9\end{array}$


7. If I were an employer looking to hire, I might avoid hiring a fat person.

$\begin{array}{llllllllll}0 & 1 & 2 & 3 & 4 & 5 & 6 & 7 & 8 & 9\end{array}$

Fear of Fat

8. I feel disgusted with myself when I gain weight.

$\begin{array}{llllllllll}0 & 1 & 2 & 3 & 4 & 5 & 6 & 7 & 8 & 9\end{array}$

9. One of the worst things that could happen to me would be if I gained 25 pounds.

$\begin{array}{llllllllll}0 & 1 & 2 & 3 & 4 & 5 & 6 & 7 & 8 & 9\end{array}$

10. I worry about becoming fat.

$\begin{array}{llllllllll}0 & 1 & 2 & 3 & 4 & 5 & 6 & 7 & 8 & 9\end{array}$

Willpower

11. People who weigh too much could lose at least some part of their weight through a little exercise.

$\begin{array}{llllllllll}0 & 1 & 2 & 3 & 4 & 5 & 6 & 7 & 8 & 9\end{array}$

12. Some people are fat because they have no willpower.

$\begin{array}{llllllllll}0 & 1 & 2 & 3 & 4 & 5 & 6 & 7 & 8 & 9\end{array}$

13. Fat people tend to be fat pretty much through their own fault. ${ }^{1}$

$\begin{array}{llllllllll}0 & 1 & 2 & 3 & 4 & 5 & 6 & 7 & 8 & 9\end{array}$

${ }^{1}$ Crandall, C.S. (1994). Prejudice against fat people: Ideology and self-interest. Journal of Personality and Social Psychology, 66, 882-894. 


\section{Fat Phobia Scale}

Listed below are 14 pairs of adjectives sometimes used to describe obese or fat people. For each adjective pair, please place an $\mathrm{X}$ on the line closest to the adjective that you feel best describes your feelings and beliefs.

1 Lazy
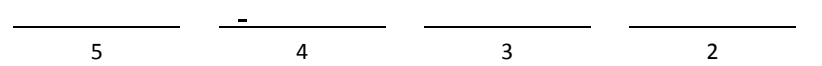

industrious

2 no will power
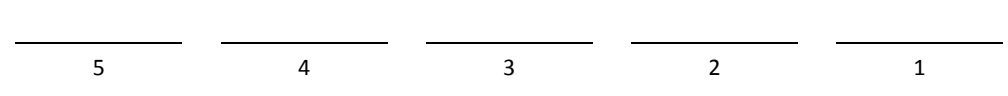

3 Attractive
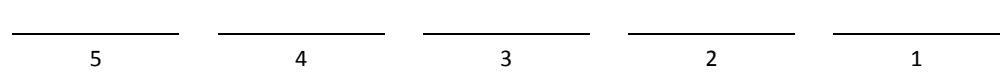

4 good self-control
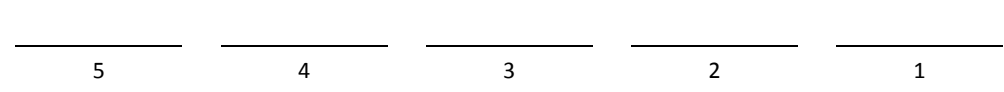

poor self-control

5 Fast

$$
5
$$

having

6 endurance
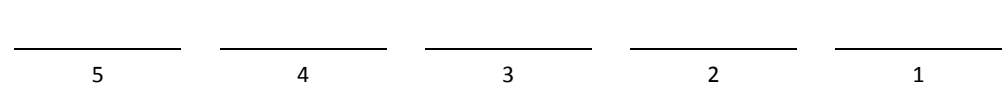

having no endurance

7 Active
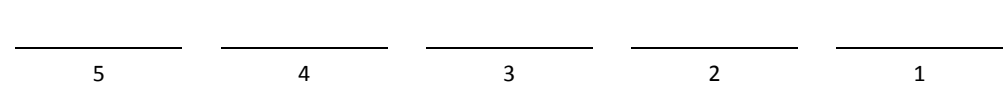

8 Weak
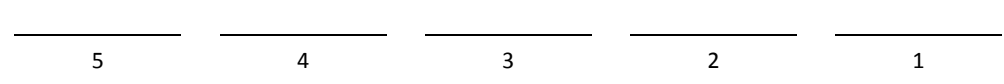

9 self-indulgent
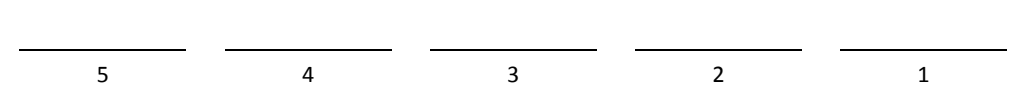

10 dislikes food
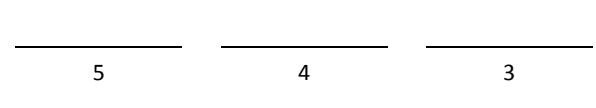

11 Shapeless
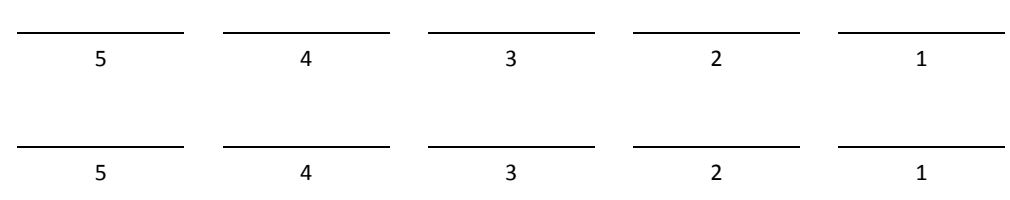

12 Undereats
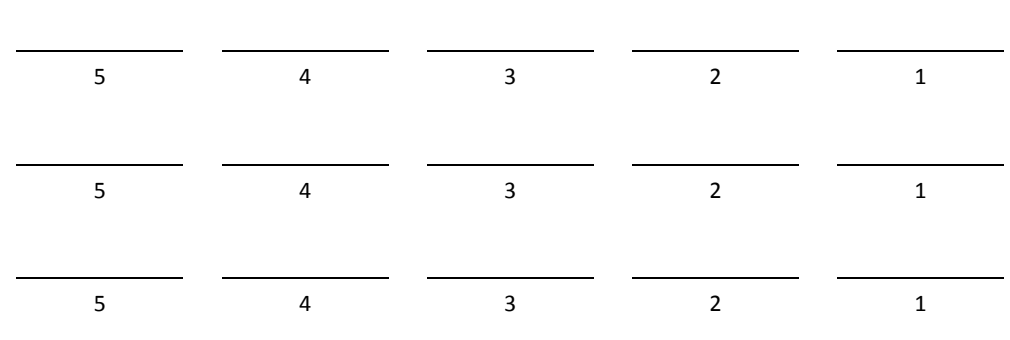

13 Insecure
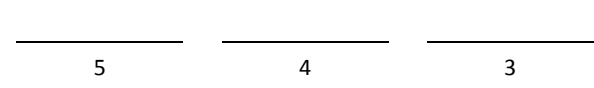

14 low self-esteem
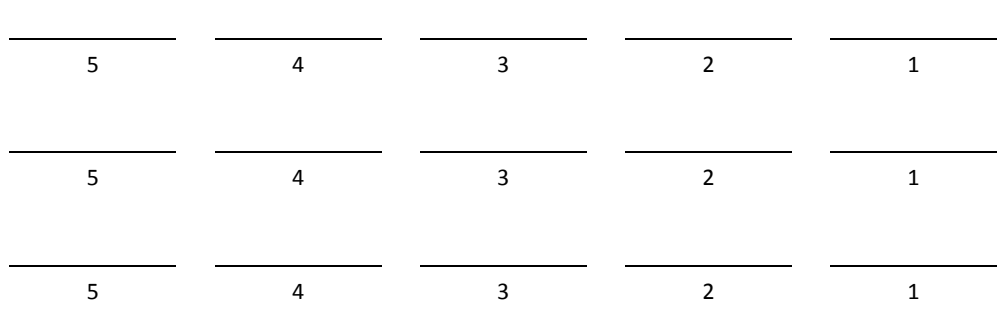

inactive

strong

self-sacrificing

likes food

shapely

overeats

secure

high self-esteem

2

${ }^{22}$ The Rudd Center for Food Policy and Obesity, Yale University 


\section{APPENDIX C: Survey Documents for Registered Dietitians}

\section{Comparison of Obesity Bias, Attitudes, and Beliefs Among Undergraduate Dietetic Students, Dietetic Interns, and Practicing Registered Dietitians}

Thank you for supporting our research by completing this survey. We realize that your time is valuable and we appreciate your participation. The purpose of this research is to compare attitudes, beliefs, and bias concerning obesity among undergraduate dietetic students, dietetic interns, and practicing registered dietitians in Middle Tennessee, East Tennessee, and Northeast Mississippi. The procedures, which will involve you as a research subject, include completing this survey that will take about 5 minutes of your time. Participation in this research experiment is voluntary. You may refuse to participate. You can quit at any time. If you quite or refuse to participate, the benefits or treatment to which you are otherwise entitled will not be affected. You may quit by contacting Sarah Welborn at welborns@goldmail.etsu.edu or Dr. Michelle Lee at 423-439-7524 or leeml2@etsu.edu. For questions, comments or concerns, please contact Sarah Welborn at welborns@goldmail.etsu.edu or Dr. Michelle Lee at 423-439-7524 or leeml2@etsu.edu. You may contact the ETSU Institutional Review Board at 423-439-6054 for any questions you may have about your rights as a research subject. By continuing to answer the questions in the rest of the survey, you confirm that you have read this document.

\section{Demographics}

Height: (pounds)

Weight: (feet and inches)

Sex: Male Female

Age:

Race/ethnicity: White

African American

Hispanic

Other

State:

Tennessee

Mississippi

1. How long have you been a practicing Registered Dietitian?

2. Where do you work?

3. What area of dietetics do you work in?

Circle the best answer for the following:

1. Do you have a family history of overweight/obesity? Yes

2. Do you have a personal history of overweight/obesity? Yes No

3. Have you ever had a close friend who was overweight or obese? Yes

4. How would you describe most of your closest friends?
a. Underweight
b. Normal/Average Weight
c. Overweight

5. How would you describe yourself?

a. Underweight 
b. Normal/Average Weight

c. Overweight

\section{Antifat Attitudes Questionnaire (AFA) ${ }^{1}$}

The AFA is scored using a Likert-type response format ( 0 = very strongly disagree; $9=$ very strongly agree). Higher scores indicate stronger anti-fat attitudes. Pick the response that best represents your attitude or belief.

$\begin{array}{llllllll}0 & \text { very strongly disagree } & 3 & \text { somewhat disagree } & 6 & \text { somewhat agree } & 9 & \text { very strongly agree } \\ 1 & \text { strongly disagree } & 4 & \text { disagree } & 7 & \text { moderately agree } & & \\ 2 & \text { moderately disagree } & 5 & \text { agree } & 8 & \text { strongly agree } & \end{array}$

\section{Dislike}

1. I really don’t like fat people much.

$\begin{array}{llllllllll}0 & 1 & 2 & 3 & 4 & 5 & 6 & 7 & 8 & 9\end{array}$

2. I don't have many friends that are fat.

$\begin{array}{llllllllll}0 & 1 & 2 & 3 & 4 & 5 & 6 & 7 & 8 & 9\end{array}$

3. I tend to think that people who are overweight are a little untrustworthy.

$\begin{array}{llllllllll}0 & 1 & 2 & 3 & 4 & 5 & 6 & 7 & 8 & 9\end{array}$

4. Although some fat people are surely smart, in general, I think they tend not to be quite as bright as normal weight people.

$\begin{array}{llllllllll}0 & 1 & 2 & 3 & 4 & 5 & 6 & 7 & 8 & 9\end{array}$

5. I have a hard time taking fat people too seriously.

$\begin{array}{llllllllll}0 & 1 & 2 & 3 & 4 & 5 & 6 & 7 & 8 & 9\end{array}$

6. Fat people make me somewhat uncomfortable.

$\begin{array}{llllllllll}0 & 1 & 2 & 3 & 4 & 5 & 6 & 7 & 8 & 9\end{array}$


7. If I were an employer looking to hire, I might avoid hiring a fat person.

$\begin{array}{llllllllll}0 & 1 & 2 & 3 & 4 & 5 & 6 & 7 & 8 & 9\end{array}$

Fear of Fat

8. I feel disgusted with myself when I gain weight.

$\begin{array}{llllllllll}0 & 1 & 2 & 3 & 4 & 5 & 6 & 7 & 8 & 9\end{array}$

9. One of the worst things that could happen to me would be if I gained 25 pounds.

$\begin{array}{llllllllll}0 & 1 & 2 & 3 & 4 & 5 & 6 & 7 & 8 & 9\end{array}$

10. I worry about becoming fat.

$\begin{array}{llllllllll}0 & 1 & 2 & 3 & 4 & 5 & 6 & 7 & 8 & 9\end{array}$

Willpower

11. People who weigh too much could lose at least some part of their weight through a little exercise.

$\begin{array}{llllllllll}0 & 1 & 2 & 3 & 4 & 5 & 6 & 7 & 8 & 9\end{array}$

12. Some people are fat because they have no willpower.

$\begin{array}{llllllllll}0 & 1 & 2 & 3 & 4 & 5 & 6 & 7 & 8 & 9\end{array}$

13. Fat people tend to be fat pretty much through their own fault. ${ }^{3}$

$\begin{array}{llllllllll}0 & 1 & 2 & 3 & 4 & 5 & 6 & 7 & 8 & 9\end{array}$

${ }^{3}$ Crandall, C.S. (1994). Prejudice against fat people: Ideology and self-interest. Journal of Personality and Social Psychology, 66, 882-894. 


\section{Fat Phobia Scale}

Listed below are 14 pairs of adjectives sometimes used to describe obese or fat people. For each adjective pair, please place an $\mathrm{X}$ on the line closest to the adjective that you feel best describes your feelings and beliefs.

1 Lazy
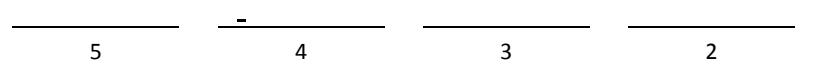

industrious

2 no will power
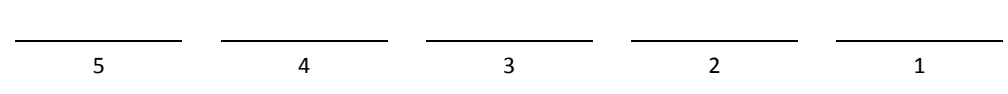

3 Attractive
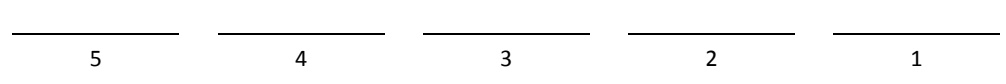

4 good self-control
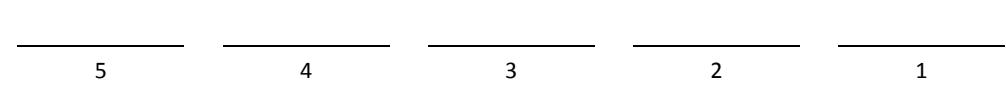

poor self-control

5 Fast

$$
5
$$

having

6 endurance
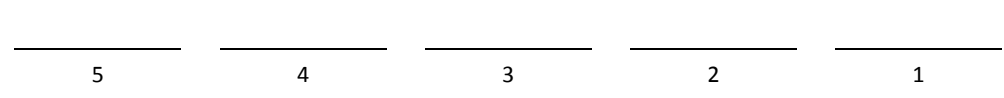

having no endurance

7 Active
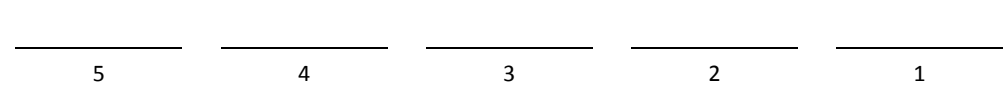

8 Weak
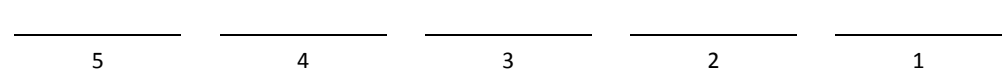

9 self-indulgent
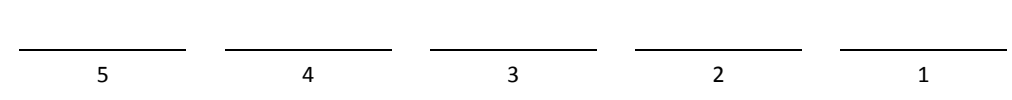

10 dislikes food
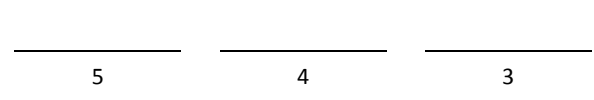

11 shapeless
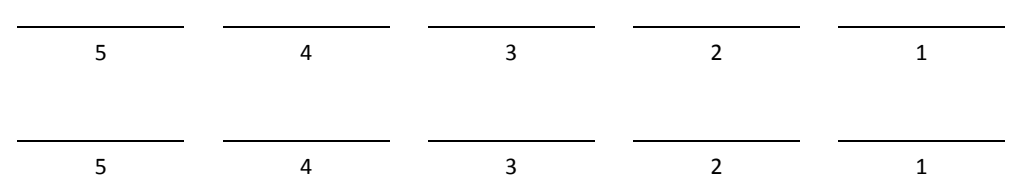

12 undereats
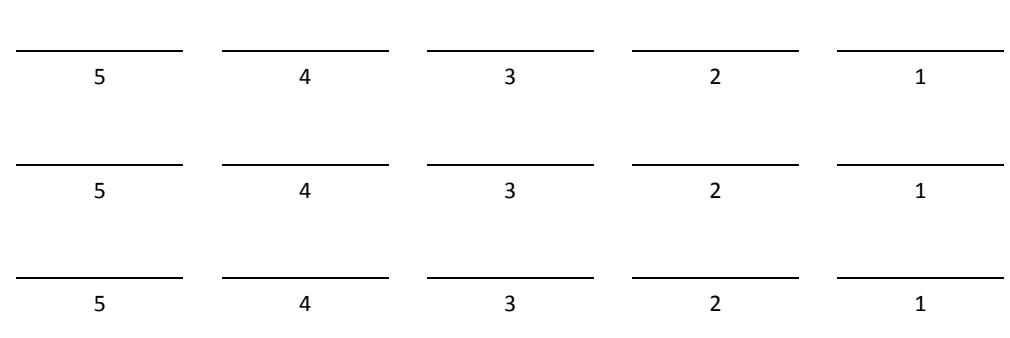

13 insecure
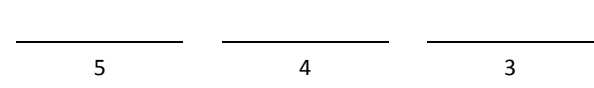

14 low self-esteem
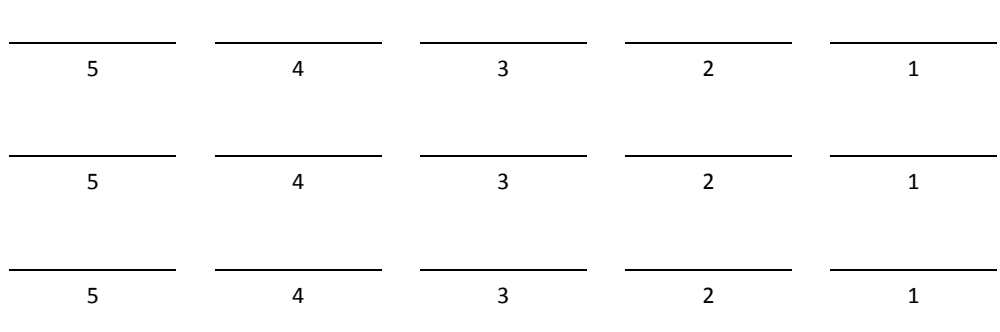

inactive

strong

self-sacrificing

likes food

shapely

overeats

secure

high self-esteem

4

${ }^{44}$ The Rudd Center for Food Policy and Obesity, Yale University 


\section{VITA}

\section{SARAH ELIZABETH WELBORN}

Personal Data:

Education:

Professional Experience:

Honors and Awards:
Date of Birth: October 26, 1988

Place of Birth: Nashville, Tennessee

Marital Status: Engaged

Ezell-Harding Christian School, Antioch, Tennessee

B.S. Nutrition and Food Science/Dietetics, Middle Tennessee State University, Murfreesboro, Tennessee 2011

M.S. Clinical Nutrition, East Tennessee State University, Johnson City, Tennessee 2013

Dietetic Intern, East Tennessee State University, Johnson City, Tennessee, 2011-2013

Teacher's Assistant, East Tennessee State University, Department of Allied Health Sciences, Clinical Nutrition, 2011-2012

Nutrition and Food Sciences Outstanding Senior, Middle

Tennessee State University, 2010-2011

Senior Honor Student, Middle Tennessee State University, 20102011

Lucy Dye Scholarship, Middle Tennessee State University, Human Sciences Department, 2010-2011

Katherine Chambers Hay Scholarship, Middle Tennessee State University, Campus Recreation, 2010

Robert C. Byrd Honors Scholarship, Middle Tennessee State University, 2007-2011 
Publications:

Howell M, Welborn S. (2010). “Protein 101.” Middle Tennessee State University Health Services- contributing writer.

Welborn S. (2010). "Eating healthy on campus not impossible." Middle Tennessee State University. Sidelines Newspaper. 87 (5): 8-10.

Howell M, Welborn S. (2011). "Mathematics, Molecules, and Meals: The School's Approach to Nutrition Education.” Middle Tennessee State University Satellite and Webcasting Center Program Presenter. 